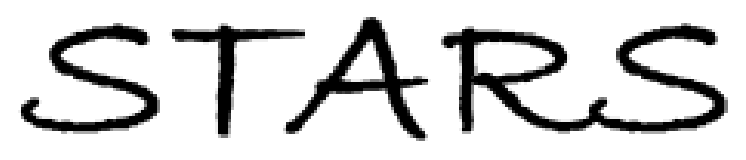

University of Central Florida

STARS

Electronic Theses and Dissertations, 2020-

2020

\title{
Modeling of Incident Type and Incident Duration Using Data from Multiple Years
}

Sudipta Dey Tirtha

University of Central Florida

Part of the Civil Engineering Commons, and the Transportation Engineering Commons

Find similar works at: https://stars.library.ucf.edu/etd2020

University of Central Florida Libraries http://library.ucf.edu

This Masters Thesis (Open Access) is brought to you for free and open access by STARS. It has been accepted for inclusion in Electronic Theses and Dissertations, 2020- by an authorized administrator of STARS. For more information, please contact STARS@ucf.edu.

\section{STARS Citation}

Tirtha, Sudipta Dey, "Modeling of Incident Type and Incident Duration Using Data from Multiple Years" (2020). Electronic Theses and Dissertations, 2020-. 623.

https://stars.library.ucf.edu/etd2020/623

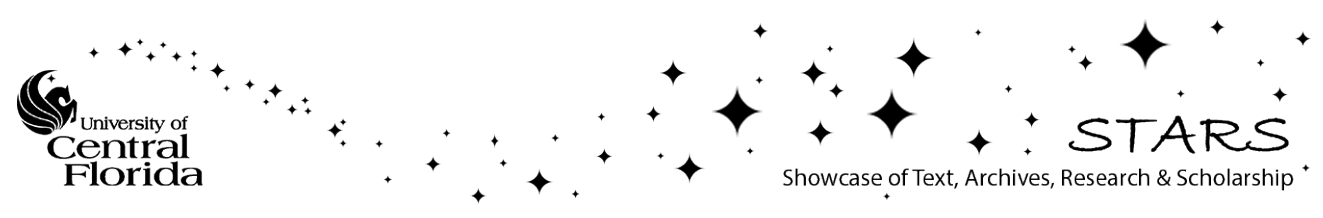




\title{
MODELING OF INCIDENT TYPE AND INCIDENT DURATION USING DATA FROM MULTIPLE YEARS
}

\author{
by \\ SUDIPTA DEY TIRTHA \\ B.Sc. Bangladesh University of Engineering and Technology, 2017

\begin{abstract}
A thesis submitted in partial fulfillment of the requirements
for the degree of Master of Science

in the Department of Civil, Environmental and Construction Engineering

in the College of Engineering and Computer Science

at the University of Central Florida

Orlando, Florida
\end{abstract}

Summer Term

2020

Major Professor: Naveen Eluru 
(C) 2020 Sudipta Dey Tirtha 


\begin{abstract}
We develop a model system that recognizes the distinct traffic incident duration profiles based on incident type. Specifically, a copula-based joint framework with a scaled multinomial logit model (SMNL) system for incident type and a grouped generalized ordered logit (GGOL) model system for incident duration to accommodate for the impact of observed and unobserved effects on incident type and incident duration. The model system is estimated using traffic incident data from 2012 through 2017 for the Greater Orlando region, employing a comprehensive set of exogenous variables - incident characteristics, roadway characteristics, traffic condition, weather condition, built environment and socio-demographic characteristics. In the presence of multiple years of data, the copula-based methodology is also customized to accommodate for observed and unobserved temporal effects (including heteroscedasticity) on incident duration. Based on a rigorous comparison across different copula models, parameterized Frank-Clayton-Frank specification was found to offer the best data fit. The value of the proposed model system is illustrated by comparing predictive performance of the proposed model relative to the traditional single duration model on a holdout sample.
\end{abstract}

Keywords: Incident type; Incident duration; Scaled multinomial logit; Grouped generalized ordered logit; Joint framework 


\section{ACKNOWLEDGMENT}

I would like to convey my sincere gratitude and thanks to my honorable supervisor Dr. Naveen Eluru for his excellent supervision and also for his constant support in this thesis.

I would also like to gratefully acknowledge Florida Department of Transportation (FDOT) for providing access to traffic incident management data for Greater Orlando region.

I would further like to convey my heartiest gratitude to Dr. Shamsunnahar Yasmin for her constant mentoring throughout this thesis. 


\section{TABLE OF CONTENTS}

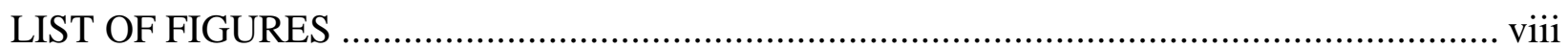

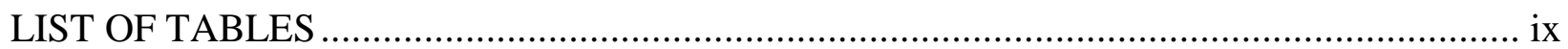

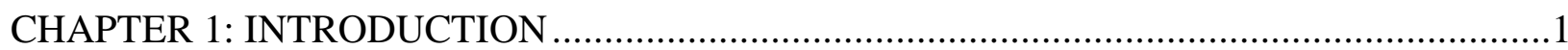

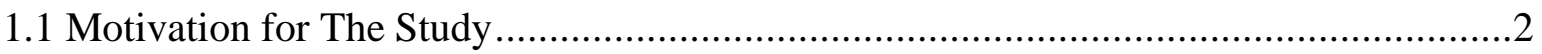

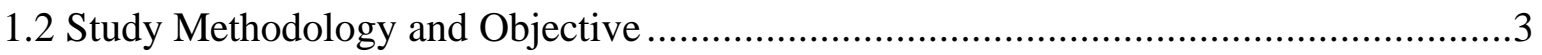

1.3 Thesis Structure

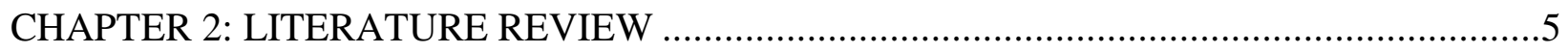

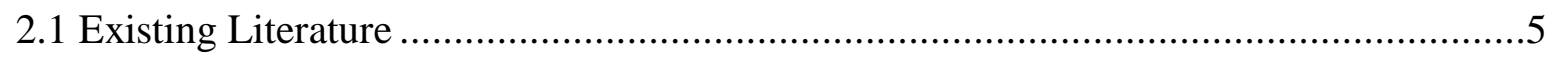

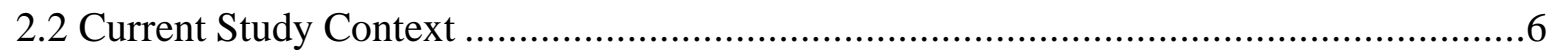

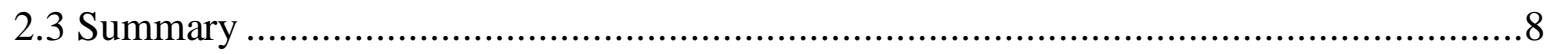

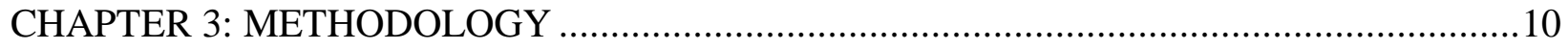

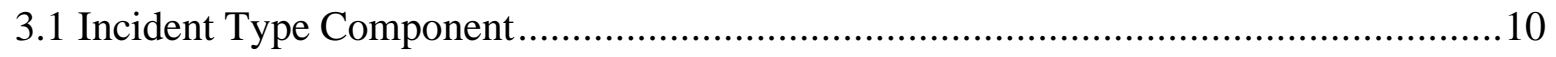

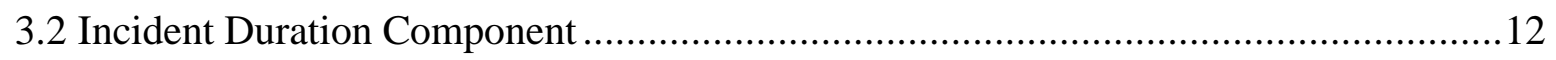

3.3 The Joint Model: A Copula Based Approach ........................................................14

3.3.1 Estimation Procedure...............................................................................16

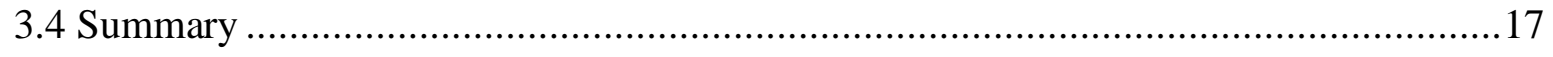

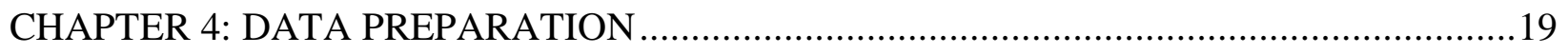

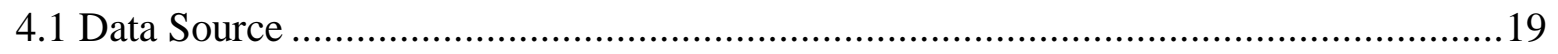




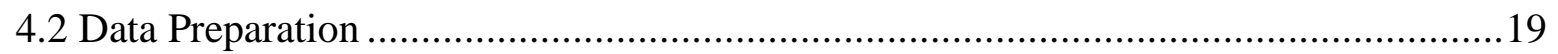

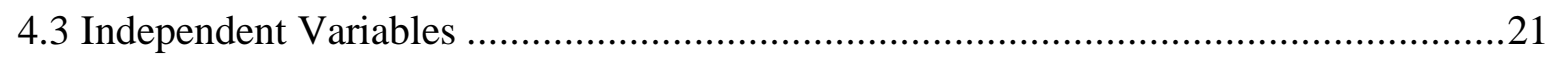

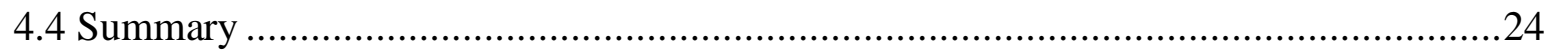

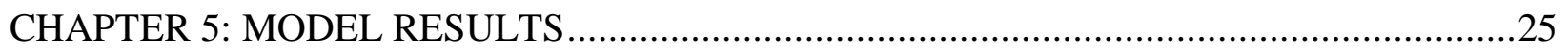

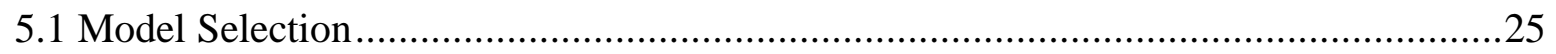

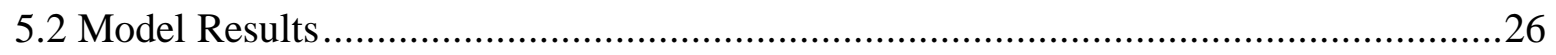

5.2.1 Incident Type Model Component.................................................................22

5.2.1.1 Roadway Characteristics.................................................................2

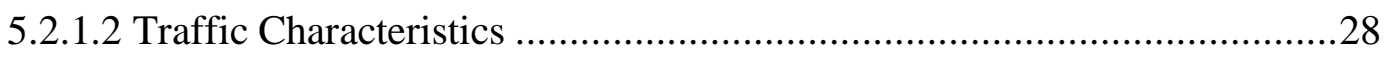

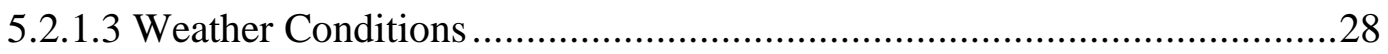

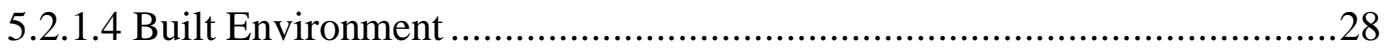

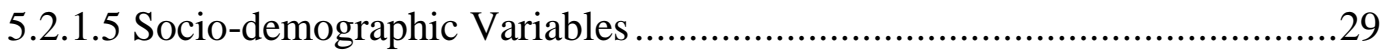

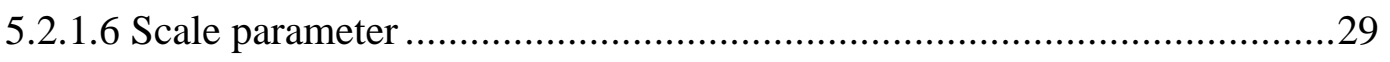

5.2.2 Incident Duration Model Component..............................................................

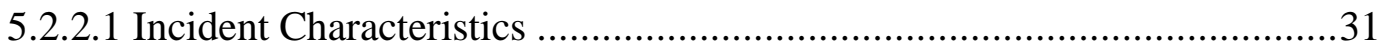

5.2.2.2 Roadway Characteristics......................................................................... 31

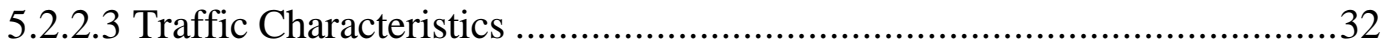

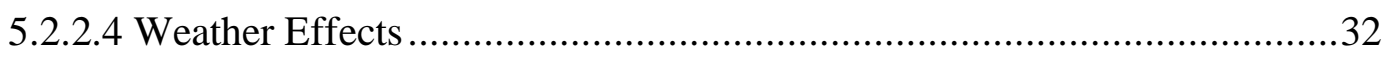

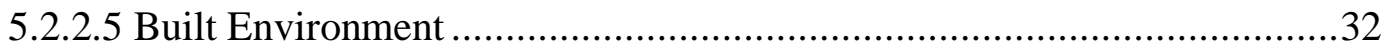




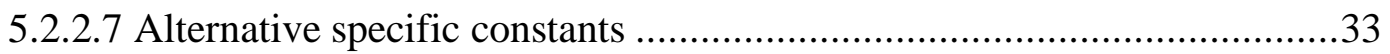

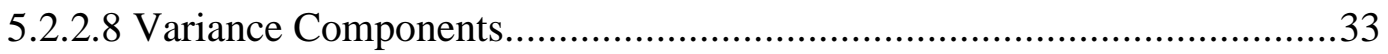

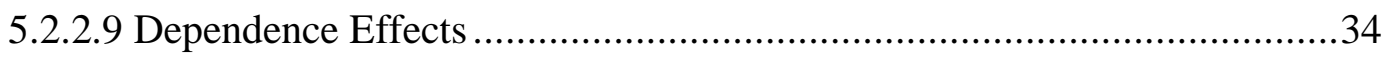

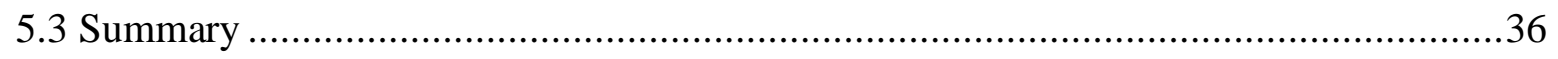

CHAPTER 6: MODEL PERFORMANCE AND APPLICATION ……………........................

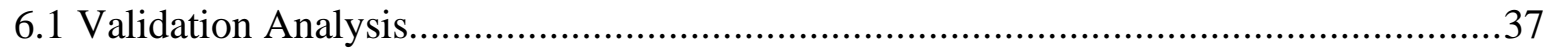

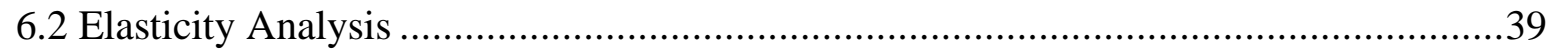

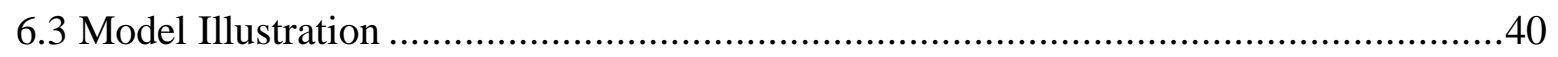

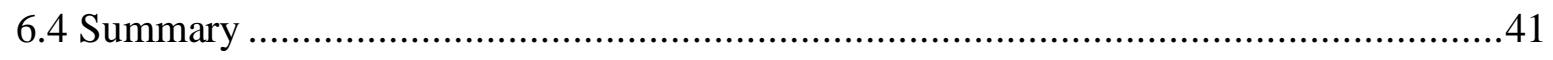

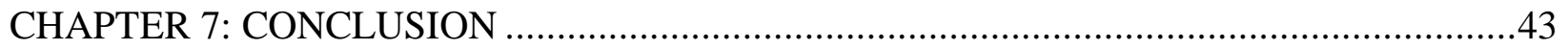

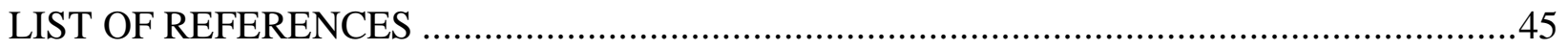




\section{LIST OF FIGURES}

Figure 4.1 Distribution of Incident Duration for Different Incident Types ............................20

Figure 6.1 Comparison of Predictive Log-likelihood of the Three Models ..............................38

Figure 6.2 Response Surface for Predicted Incident Frequencies ......................................42 


\section{LIST OF TABLES}

Table 2.1 Summary of Literature Review ............................................................ 9

Table 4.1 Description of Model Estimation Sample ..................................................21

Table 5.1 Parameter Estimates for Incident Type Component (SMNL Model Results) .............29

Table 5.2 Parameter Estimates for Incident Duration ....................................................34

Table 6.1 Elasticity Analysis for Incident Duration ..................................................40 


\section{CHAPTER 1: INTRODUCTION}

The prevalence of sub-urban life in North American cities in the latter half of the $20^{\text {th }}$ century and early $21^{\text {st }}$ century has resulted in an over-reliance on the private vehicle mode. The high private vehicle dependency burdens existing roadway infrastructure resulting in high congestion levels in metropolitan areas. Specifically, the economic costs of traffic congestion direct costs (time and fuel wastage) and indirect costs (increase in transportation costs) - amount to nearly 305 billion dollars in 2017 (INRIX, 2018). The annual economic costs add up to nearly $\$ 3000$ per resident in large urban regions such as Los Angeles and New York City. Traffic congestion can generally be attributed to either recurring or non-recurring events. Congestion arising from recurring events is generally a result of mismatched transportation demand and supply (or capacity). Non-recurring congestion, on the other hand, is a result of unexpected (or irregular) events such as abandoned vehicles, adverse weather, spilled loads, highway debris, and traffic crashes. It is estimated that delays arising from non-recurring congestion contribute between 40 to $60 \%$ of total congestion delays on the US highways (Tavassoli Hojati et al., 2013). Among nonrecurring events, the US Department of Transportation (DOT) reports that traffic incidents alone contribute to $25 \%$ of the total delays leading to an annual loss of about 2.8 billion gallons of gasoline (FHWA EDC, 2012). The proposed research contributes to reducing traffic congestion on roadways by understanding the factors influencing incident duration and providing remedial solutions to improve clearance times.

The overall incident duration, as identified by the Highway Capacity Manual (HCM 2010), is composed of the following four phases: Notification time, Response time, Clearance time and Traffic recovery time. The first three phases are directly affected by the traffic incident and the incident management response infrastructure in the urban region. On the other hand, the traffic 
recovery time (fourth phase) is a function of total duration of the first three phases and the traffic demand on the facility. Any improvements in reducing the duration of the first three phases of the incident will contribute to lower traffic recovery time.

\subsection{Motivation for The Study}

In earlier studies, while the importance of incident type has been highlighted in incident duration modeling, it is mostly considered as an independent variable. The consideration potentially imposes several major restrictions on the analysis approaches. First, the analysis approaches restrict the influence of independent variables to be the same across all incident types i.e. the incident duration profile is restricted to be the same across all incident types. The only variation across incident types is estimated through the incident type indicator variables. However, it is possible that the impact of various independent variables is moderated by the incident type indicator. For example, consider the difference between two incidents: a traffic crash and an abandoned vehicle on roadway. In the traffic crash event, given the potential possibility of injury (or even fatality), the resource deployment urgency might be significantly different relative to the abandoned vehicle incident. This is an example of the same infrastructure availability acting at a different pace based on incident type. It is plausible to consider that several other independent variable effects are also affected by incident type.

Second, factors that have led to a particular incident might also affect the incident duration. For instance, the absence of a shoulder on a roadway facility reduces room for error and might lead to traffic crashes. The same factor by not allowing adequate room for traffic incident management vehicles might result in longer incident clearance times. This is an example of an observed factor (absence of a shoulder) influencing incident type and incident duration. Such 
factors can be easily considered in the incident duration model. However, it is also possible that various unobserved factors that affect incident type might also influence incident duration. Consider a roadway facility that has a high share of tourist drivers that are unfamiliar with the roadway. In the presence of tourist drivers, the probability of a traffic crash might be higher. In this scenario, traffic incident management vehicles might also take longer to arrive at the scene as the tourist drivers are not aware of the appropriate maneuvers to allow these vehicles. While it is possible to ascertain locations with higher presence of tourist drivers, it is close to impossible to determine the exact share of these drivers on roadways. Thus, we have an unobserved factor (share of tourist drivers) on roadway facility that may affect incident type and incident duration. Accommodating for the influence of unobserved factors warrants the development of a model system that examines incident type and incident duration as a joint distribution. Finally, earlier research typically employed one cross-sectional sample of data for incident duration analysis. However, with availability of data for several years from various transportation agencies, it is important to develop model structures that incorporate for the influence of temporal factors (observed and unobserved) in modeling incident duration.

\subsection{Study Methodology and Objective}

Toward addressing the aforementioned issues, the current study aims to develop a copula based joint model system with a scaled multinomial logit model (SMNL) system for incident type and a grouped generalized ordered logit (GGOL) model system for incident duration. While the

scaled model accommodates for common unobserved heterogeneity by allowing the variance of the unobserved component to vary by time period, the grouped generalized ordered system offers a flexible non-linear formulation for modeling duration variables. The proposed model is estimated 
using FDOT's traffic incident management data from 2012 to 2017 for Greater Orlando region. In the presence of multiple years of data, the copula-based methodology accommodates for observed and unobserved temporal effects (including heteroscedasticity) on incident duration. Furthermore, performance of the developed model is examined by a validation test using a holdout sample by comparing with the traditional model (a single duration model using incident type as an independent variable) and the independent models of incident duration (separate duration models by incident type). The validation results clearly indicates the superiority of the proposed copula based model. Finally, application of the developed model is illustrated in this study. Model illustrations provide incident frequency plots against incident duration and selected attributes for different incident types.

\subsection{Thesis Structure}

The rest of the thesis is organized as follows: Chapter 2 provides a brief review of previous relevant researches and positions the current study on incident type and incident duration modelling. Chapter 3 describes the formulation and estimation procedure of the proposed copula based joint model. Chapter 4 discusses a detailed summary of the data source and exogenous variables considered for the analysis. Model estimation results are presented in chapter 5 in which the analysis results are discussed in detail. Furthermore, a validation exercise has been undertaken by comparing the proposed copula based model, the independent model and the traditional model which is described in Chapter 6. Besides, Chapter 6 presents the Elasticity Analysis and Model Application. Finally, a summary of study findings and conclusions are presented in Chapter 7. 


\section{CHAPTER 2: LITERATURE REVIEW}

Earlier studies identify the factors of incident duration and its components using both parametric and non-parametric models. This chapter describes the existing literature in detail and positions the current context of this study.

\subsection{Existing Literature}

Given the significant influence of traffic incidents on roadways, several research efforts have examined the factors influencing incident duration focusing either on total duration or the individual components of duration. Recent studies related to incident duration modeling are summarized in Table 2.1 (please see Laman et al., 2018 for a review of earlier studies). However, several observations can be concluded from the previous studies. First, the most commonly employed outcome variable includes total incident duration and duration of individual incident components (such as reporting time, response time and clearance time). Second, separate duration model for a certain incident type is modelled in few studies (Chung, 2010; Chung et al., 2015; Hong et al., 2019) i.e. accident duration model. Third, in earlier studies, the methodologies can be broadly classified into two groups: parametric methods and non-parametric methods. Among parametric methods, the commonly used methodologies include (a) Linear regression analysis (Garib et al., 2002; Javid and Javid, 2017), (b) Truncated regression based time sequential method (Khattak et al., 2007), (c) Parametric hazard-based model (Haule et al., 2019; Chung, 2010; Junhua et al., 2013; Tavassoli Hojati et al., 2013, 2014; Ghosh et al., 2014; Chung et al., 2015; Li et al., 2015; Nam and Mannering, 2000; Hong et al., 2019; Ke et al., 2018) (d) Copula based joint model of incident components (Laman et al., 2018; Zou et al., 2018), (e) Binary probit and regression model based joint framework (Ding et al., 2015). In terms of non-parametric methods, approaches 
employed include (a) Tree based model (Valenti et al., 2010; Zhan et al., 2011; Hamad et al., 2020; Shang et al., 2019; Ke et al., 2018; Ma et al., 2017), (b) Bayesian networks (Ozbay and Noyan, 2006), (c) Support vector machine (Valenti et al., 2010; Wu et al., 2011), (d) Artificial neural network (Lee and Wei, 2010), (e) Partial least square regression (Wang et al., 2013), (f) Knearest neighbor (Wang et al., 2018). Fourth, none of the studies reviewed examined incident type and incident duration as a joint distribution. Instead, incident type was considered as an independent variable for modeling incident duration. Fifth, based on these models developed, the most important independent variables identified in literature include: incident characteristics (such as incident type, number of responders involved, first responder), roadway characteristics (such as functional classification, geometric characteristics, Average Annual Daily Traffic (AADT), Truck AADT), traffic conditions (such as time of the day, weekday/weekend), and weather conditions (such as season, rain, temperature).

\subsection{Current Study Context}

Earlier studies clearly highlight the emphasis on incident type in duration modeling and it is mostly used as an independent variable. But this consideration imposes several major restrictions in analysis procedure (see Chapter 1 for the detailed discussion). Toward addressing the aforementioned issues, the current study develops a joint model system with a scaled multinomial logit model (SMNL) system for incident type and a grouped generalized ordered logit (GGOL) model system for incident duration. The scaled model accommodates for common unobserved heterogeneity by allowing the variance of the unobserved component to vary by time period (see 
Mannering, 2018 for discussion on temporal instability $)^{1}$. The grouped generalized ordered system (employed in Laman et al., 2018) offers a flexible non-linear formulation for modeling duration variables. The approach retains a parametric form similar to traditional hazard duration models while also allowing for alternative specific effects. The two model components are stitched together as a joint distribution using the flexible copula-based approach. In the presence of multiple years of data, the copula-based methodology was also customized to accommodate for observed and unobserved temporal effects (including heteroscedasticity) on incident duration. In our analysis, we employ six different copula structures - the Gaussian copula, the Farlie-GumbelMorgenstern (FGM) copula, and set of Archimedean copulas including Frank, Clayton, Joe and Gumbel copulas (a detailed discussion of these copulas is available in Bhat and Eluru, 2009). The model system is estimated using traffic incident data from 2012 through 2017 for the Greater Orlando region. The incident data is augmented with a host of independent variables including traffic characteristics, roadway characteristics, incident characteristics, weather conditions, built environment and socio-demographic characteristics. Further, the value of the proposed model system is illustrated by comparing predictive performance of the proposed model relative to a single incident duration model (ignoring incident type profile) on a holdout sample (not used in estimation). The reader would note that such joint model systems have been employed in travel

${ }^{1}$ In transportation research domain, most recently, several studies have addressed parameter stability over time (see Behnood and Mannering (2015), Marcoux et al. (2018), Anowar et al. (2016), Dabbour (2017)). A detailed review of these articles is beyond of scope of current study. Mannering (2018) presented a detailed discussion on temporal instability. 
behavior and transportation safety literature. However, to the best of the authors' knowledge, it is the first application in the incident duration modeling area.

\subsection{Summary}

This chapter provides a detailed discussion of existing literature related to incident duration modeling. Besides, the current study context is also described in this chapter. The next chapter will describe econometric methodology used in this study. 
Table 2.1 Summary of Literature Review

\begin{tabular}{|c|c|c|c|c|c|c|c|c|c|}
\hline \multirow[b]{2}{*}{ Study } & \multirow{2}{*}{$\begin{array}{l}\text { Study } \\
\text { region }\end{array}$} & \multirow[b]{2}{*}{ Objectives } & \multirow{2}{*}{$\begin{array}{l}\text { Methodology } \\
\text { Adopted }\end{array}$} & \multicolumn{6}{|c|}{ Independent Variables Considered } \\
\hline & & & & $\begin{array}{l}\text { Incident } \\
\text { Charac. }\end{array}$ & $\begin{array}{l}\text { Traffic } \\
\text { Condition } \\
\end{array}$ & $\begin{array}{l}\text { Roadway } \\
\text { Charac. }\end{array}$ & $\begin{array}{l}\text { Land } \\
\text { Use }\end{array}$ & $\begin{array}{l}\text { Built } \\
\text { Environ. }\end{array}$ & $\begin{array}{l}\text { Weather } \\
\text { Condition }\end{array}$ \\
\hline $\begin{array}{l}\text { Hamad } \\
\text { et al., } \\
2020\end{array}$ & $\begin{array}{l}\text { Houston, } \\
\text { Texas; 2004- } \\
2013 \\
\end{array}$ & $\begin{array}{l}\text { To develop a model to } \\
\text { predict incident duration }\end{array}$ & $\begin{array}{l}\text { Random forest } \\
\text { regressor and ANN }\end{array}$ & Yes & Yes & Yes & No & No & Yes \\
\hline $\begin{array}{l}\text { Haule et } \\
\text { al., } 2019\end{array}$ & $\begin{array}{l}\text { Jacksonville, } \\
\text { Florida; } \\
2015-2016\end{array}$ & $\begin{array}{l}\text { To model incident impact } \\
\text { duration and clearance } \\
\text { duration }\end{array}$ & $\begin{array}{l}\text { Hazard based duration } \\
\text { model }\end{array}$ & No & Yes & Yes & No & No & No \\
\hline $\begin{array}{l}\text { Hong et } \\
\text { al., } 2019\end{array}$ & $\begin{array}{l}\text { Korean } \\
\text { expressway; } \\
2007-2017\end{array}$ & $\begin{array}{l}\text { To identify the relationship } \\
\text { between crash } \\
\text { characteristics and accident } \\
\text { duration for trucks } \\
\text { transporting HAZMAT }\end{array}$ & $\begin{array}{l}\text { Random parameters } \\
\text { hazard-based model }\end{array}$ & Yes & Yes & Yes & No & No & Yes \\
\hline $\begin{array}{l}\text { Shang et } \\
\text { al., } 2019\end{array}$ & $\begin{array}{l}\text { Interstate } \\
880, \text { China }\end{array}$ & $\begin{array}{l}\text { To develop a novel } \\
\text { prediction method to predict } \\
\text { incident duration }\end{array}$ & NCA-BOA-RF & Yes & No & No & No & No & Yes \\
\hline $\begin{array}{l}\text { Laman } \\
\text { et. al., } \\
2018\end{array}$ & $\begin{array}{l}\text { District 5, } \\
\text { Florida; } \\
2015\end{array}$ & $\begin{array}{l}\text { To jointly model reporting } \\
\text { time, response time and } \\
\text { clearance time }\end{array}$ & $\begin{array}{l}\text { Copula based joint } \\
\text { framework; group } \\
\text { ordered logit model }\end{array}$ & Yes & Yes & Yes & No & Yes & Yes \\
\hline $\begin{array}{l}\text { Ke et al., } \\
2018\end{array}$ & $\begin{array}{l}\text { Shanghai } \\
\text { urban } \\
\text { expressways; } \\
2014\end{array}$ & $\begin{array}{l}\text { To propose a hybrid model } \\
\text { to establish incident } \\
\text { duration prediction }\end{array}$ & $\begin{array}{l}\text { Cox } \\
\text { regression and random } \\
\text { survival forests } \\
\text { algorithm }\end{array}$ & Yes & Yes & Yes & No & No & Yes \\
\hline $\begin{array}{l}\text { Wang et } \\
\text { al., } 2018\end{array}$ & $\begin{array}{l}\text { Beijing; } \\
2008\end{array}$ & $\begin{array}{l}\text { To develop a nonparametric } \\
\text { incident duration model }\end{array}$ & K-nearest neighbor & Yes & Yes & No & No & Yes & No \\
\hline $\begin{array}{l}\text { Zou et } \\
\text { al., } 2018\end{array}$ & $\begin{array}{l}\text { Seattle, } \\
\text { Washington } \\
\text { State; } 2009\end{array}$ & $\begin{array}{l}\text { To jointly model incident } \\
\text { clearance and response time }\end{array}$ & $\begin{array}{l}\text { Copula based joint } \\
\text { model; survival } \\
\text { models }\end{array}$ & Yes & Yes & Yes & No & No & Yes \\
\hline $\begin{array}{l}\text { Javid } \\
\text { and } \\
\text { Javid, } \\
2017\end{array}$ & $\begin{array}{l}\text { California; } \\
\text { 2012-2014 }\end{array}$ & $\begin{array}{l}\text { To estimate travel time } \\
\text { variability caused by traffic } \\
\text { incidents }\end{array}$ & Regression model & Yes & Yes & No & No & No & Yes \\
\hline $\begin{array}{l}\text { Ma et } \\
\text { al., } 2017\end{array}$ & $\begin{array}{l}\text { Interstate 5, } \\
\text { Washington } \\
\text { State; } 2012\end{array}$ & $\begin{array}{l}\text { To identify the influential } \\
\text { factors } \\
\text { on incident clearance time }\end{array}$ & $\begin{array}{l}\text { Gradient boosting } \\
\text { decision trees }\end{array}$ & Yes & Yes & Yes & No & No & Yes \\
\hline
\end{tabular}




\section{CHAPTER 3: METHODOLOGY}

The previous chapter presented a detailed discussion of the different concepts and methodologies used in earlier researches for incident duration modelling. In this chapter, we provide details of the model frameworks employed in our study. The chapter starts with the formulation for the scaled multinomial logit model and group generalized ordered logit model and provides details of the copula based joint model subsequently.

\subsection{Incident Type Component}

Let $q(q=1,2, \ldots, Q)$, and $k(k=1,2, \ldots, K ; K=3)$ be the indices to represent incident and the corresponding incident type, respectively. In the joint framework, the modeling of incident type follows a SMNL model structure. Following the random utility theory, the propensity of an incident $q$ being incident type $k$ takes the following form:

$$
\mu_{q k}^{*}=\beta_{k} x_{q k}+\xi_{q k}
$$

where, $x_{q k}$ is a vector of independent variables and $\beta_{k}$ is a vector of unknown parameters specific to incident type $k . \xi_{q k}$ is an idiosyncratic error term (assumed to be standard type-I extreme value distributed) capturing the effect of unobserved factors on the propensity associated with incident type $k$. An incident $q$ is identified as incident type $k$ if and only if the following condition holds:

$$
\mu_{q k}^{*}>\max _{l=1,2, \ldots, K, l \neq K} \mu_{q l}^{*}
$$


The functional form presented in Equation (2) can also be represented as binary outcome models for each incident type $k$. For example, let $\eta_{q k}$ be a dichotomous variable with binary outcome $\eta_{q k}=1$ if an incident be incident type $k$ and $\eta_{q k}=0$ if otherwise. Let us define $v_{q k}$ as follows:

$$
v_{q k}=\xi_{q k}-\left\{\max _{l=1,2, \ldots, K, l \neq K} \mu_{q l}^{*}\right\}
$$

Now, using equation (1), we can rewrite equation (3) as:

$$
v_{q k}=\mu_{q k}^{*}-\beta_{k} x_{q k}-\left\{\max _{l=1,2, \ldots, K, l \neq K} \mu_{q l}^{*}\right\}
$$

We can update equation (4) as follows

$$
v_{q k}+\beta_{k} x_{q k}=\mu_{q k}^{*}-\left\{\max _{l=1,2, \ldots, K, l \neq K} \mu_{q l}^{*}\right\}
$$

Now, using Equation (2) we can conclude that the RHS of Equation (5) can be modified as $>0$, thus providing the following expression

$$
\eta_{q k}=1 \text { if } v_{q k}+\beta_{k} x_{q k}>0
$$


In Equation (6), probability distribution of incident type outcome depends on distributional assumption of $v_{q k}$, which in turn, depends on distribution of $\xi_{q k}$. Thus, an assumption of independent and identical Type I Gumbel distribution ${ }^{2}$ for $\xi_{q k}$ provides a logistic distribution of $v_{q k}$. In the presence of multiple years of data, one can also estimate the variance of the error term with an appropriate base year. To accommodate for this, a scale parameter $(\varphi)$ can be introduced to form a SMNL model and the probability expression takes the following form:

$$
\operatorname{Pr}\left(v_{q k}<v\right)=\frac{\exp \left(\frac{-v}{\varphi}\right)}{\exp \left(\frac{-v}{\varphi}\right)+\sum_{l \neq k} \exp \left(\frac{\beta_{k} x_{q l}}{\varphi}\right)}
$$

Where, $\varphi$ is the scale parameter of interest and is parameterized as $\exp (\varrho \tau)$ and $\tau$ is a set of year specific factors such as time elapsed variable (computed as the time difference between the analysis year (2012-2017) from the base year (2012) considered), thus takes the values of $0,1,2$, 3, 4 and 5 with 2012 as the base case.

\subsection{Incident Duration Component}

Let $j_{k}$ be the index for the discrete outcome that corresponds to incident duration category for incident type $k$. In joint model framework, incident duration is modelled using a GGOL

\footnotetext{
${ }^{2}$ The reader would note that under different Generalized Extreme Value distributional assumptions for $\xi_{q k}$
} (as opposed to independent and identical Type I Gumbel distribution) would result in more complex probability structures for the incident type component with and without closed form expressions. 
specification. In group ordered response model, the discrete incident duration levels $\left(y_{q k}\right)$ are assumed to be associated with an underlying continuous latent variable $\left(y_{q k}^{*}\right)$. This latent variable is typically specified as the following linear equation:

$$
y_{q k}^{*}=\alpha_{k} z_{q k}+\sigma_{j_{k}}+\varepsilon_{q k}, y_{q k}=j_{k} \text { if } \psi_{j_{k}}<y_{q k}^{*}<\psi_{j_{k}+1}
$$

where, $z_{q k}$ is a vector of exogenous variables for incident type $k$ in incident $q, \alpha_{k}$ is row of unknown parameters, $\psi_{j_{k}}$ is the observed lower bound threshold for time interval level $j_{k}$ for incident type $k . \varepsilon_{q k}$ captures the idiosyncratic effect of all omitted variables for incident type $k$. Further, $\sigma_{j_{k}}$ is vector of time interval category specific coefficient for time interval alternative $j_{k}$ for incident type $k$. The $\varepsilon_{q k}$ terms are assumed identical across incident types. The error terms are assumed to be independently logistic distributed with variance $\lambda_{q k}^{2}$. The variance vector is parameterized as follows:

$$
\lambda_{q k}=\exp \left(\delta+\rho g_{q k}\right)
$$

where, $\delta$ is a constant, $g_{q k}$ is a set of exogenous variables associated with incident type $k$ for an incident $q$ and $\rho$ is the corresponding parameters to be estimated. To be sure, $g_{q k}$ also include the time elapsed variable, thus accommodate the effect of heteroscedasticity within the grouped ordered framework. The parameterization allows for variance to be different across incidents and also across time points accommodating heteroscedasticity. The probability for incident type $k$ for time interval in category $j_{k}$ is given by: 


$$
\operatorname{Pr}\left(y_{q k}=j_{k}\right)=\Lambda\left(\frac{\psi_{j_{k}+1}-\left(\alpha_{k} z_{q k}+\sigma_{j_{k}}\right)}{\lambda_{q k}}\right)-\Lambda\left(\frac{\psi_{j_{k}}-\left(\alpha_{k} z_{q k}+\sigma_{j_{k}}\right)}{\lambda_{q k}}\right)
$$

where, $\Lambda($.$) is the cumulative standard logistic distribution.$

\subsection{The Joint Model: A Copula Based Approach}

The incident type and incident duration components discussed in previous two subsections can be brought together in the following equation system:

$$
\begin{aligned}
& \eta_{\mathrm{qk}}=1 \text { if } \beta_{k} x_{q k}>-v_{q k} \\
& y_{q k}^{*}=\alpha_{k} z_{q k}+\sigma_{j_{k}}+\varepsilon_{q k} \text { if } y_{q k}=1\left[\eta_{\mathrm{qk}}=1\right] y_{q k}^{*}
\end{aligned}
$$

However, the level of dependency between incident type and duration category of an incident depends on the type and extent of dependency between the stochastic terms $v_{q k}$ and $\varepsilon_{q k}$. These dependencies (or correlations) are explored in the current study by using a copula-based approach. In constructing the copula dependency, the random variables $\left(v_{q k}\right.$ and $\left.\varepsilon_{q k}\right)$ are transformed into uniform distributions by using their inverse cumulative distribution functions, which are then coupled or linked as a multivariate joint distribution function by applying the copula structure. Let us assume that $\Lambda_{v k}($.$) and \Lambda_{\varepsilon k}($.$) are the marginal distribution of v_{q k}$ and $\varepsilon_{q k}$, respectively. Moreover, $\Lambda_{v k, \varepsilon k}($.$) is the joint distribution of v_{q k}$ and $\varepsilon_{q k}$. Subsequently, a bivariate distribution can be generated as a joint cumulative probability distribution of uniform $[0,1]$ marginal variables $\mathrm{U}_{1}$ and $\mathrm{U}_{2}$ as below: 


$$
\begin{aligned}
& \Lambda_{v k, \varepsilon k}(v, \varepsilon)=\operatorname{Pr}\left(v_{k}<v, \varepsilon_{k}<\varepsilon\right) \\
& =\operatorname{Pr}\left(\Lambda_{v k}^{-1}\left(U_{1}\right)<v, \Lambda_{\varepsilon k}^{-1}\left(U_{2}\right)<\varepsilon\right) \\
& =\operatorname{Pr}\left(U_{1}<\Lambda_{v k}(v), U_{2}<\Lambda_{\varepsilon k}(\varepsilon)\right)
\end{aligned}
$$

The joint distribution (of uniform marginal variable) in Equation (12) can be generated by a function $C_{\theta q}(. .).($ Sklar, 1973), such that:

$$
\Lambda_{v k, \varepsilon k}\left(v, \delta_{2}\right)=C_{\theta q}\left(U_{1}=\Lambda_{v k}(v), U_{2}=\Lambda_{\varepsilon k}(\varepsilon)\right)
$$

where $\mathrm{C}_{\theta \mathrm{q}}(.,$.$) is a copula function and \theta_{\mathrm{q}}$ the dependence parameter defining the link between $\mathrm{v}_{\mathrm{qk}}$ and $\varepsilon_{\mathrm{qk}}$. It is important to note here that, the level of dependence between incident type and incident duration level can vary across incidents. Therefore, in the current study, the dependence parameter $\theta_{\mathrm{q}}$ is parameterized as a function of observed incident attributes as follows:

$$
\theta_{q}=f n\left(\gamma_{k} s_{q k}\right)
$$

where, $\mathrm{s}_{\mathrm{qk}}$ is a vector of exogenous variable, $\gamma_{\mathrm{k}}$ is a vector of unknown parameters (including a constant) specific to incident type $k$ and $f n$ represents the functional form of parameterization. In our analysis, six different copulas structure - Gaussian, FGM, Frank, Clayton, Joe and Gumbel copulas are employed. Based on the dependency parameter permissible ranges, alternate parameterization forms for the six copulas are considered in our analysis. For Normal, 
FGM and Frank Copulas, we use $\theta_{\mathrm{q}}=\gamma_{\mathrm{k}} \mathrm{s}_{\mathrm{qk}}$, for the Clayton copula we employ $\theta_{\mathrm{q}}=$ $\exp \left(\gamma_{\mathrm{k}} \mathrm{s}_{\mathrm{qk}}\right)$, and for Joe and Gumbel copulas we employ $\theta_{\mathrm{q}}=1+\exp \left(\gamma_{\mathrm{k}} \mathrm{s}_{\mathrm{qk}}\right)$.

\subsubsection{Estimation Procedure}

The joint probability that the incident $q$ is identified to be incident type $k$ and the resulting incident duration level $j_{k}$, from equation (7) and (10), can be written as:

$$
\begin{aligned}
& \operatorname{Pr}\left(\eta_{q k}=1, y_{q k}=j_{k}\right) \\
& =\operatorname{Pr}\left\{\left(\beta_{k} x_{q k}>-v_{q k}\right),\left(\left(\frac{\psi_{j_{k}-1}-\left(\alpha_{k} z_{q k}+\sigma_{j_{k}}\right)}{\lambda_{q k}}\right)<\varepsilon_{q k}<\left(\frac{\psi_{j_{k}}-\left(\alpha_{k} z_{q k}+\sigma_{j_{k}}\right)}{\lambda_{q k}}\right)\right)\right\} \\
& =\operatorname{Pr}\left\{\left(v_{q k}>-\beta_{k} x_{q k}\right),\left(\left(\frac{\psi_{j_{k}-1}-\left(\alpha_{k} z_{q k}+\sigma_{j_{k}}\right)}{\lambda_{q k}}\right)<\varepsilon_{q k}<\left(\frac{\psi_{j_{k}}-\left(\alpha_{k} z_{q k}+\sigma_{j_{k}}\right)}{\lambda_{q k}}\right)\right)\right\} \\
& =\operatorname{Pr}\left(\left(v_{q k}>-\beta_{k} x_{q k}\right),\left(\varepsilon_{q k}<\left(\frac{\psi_{j_{k}}-\left(\alpha_{k} z_{q k}+\sigma_{j_{k}}\right)}{\lambda_{q k}}\right)\right)\right) \\
& \quad-\operatorname{Pr}\left(\left(\beta_{k} x_{q k}>v_{q k}\right),\left(\varepsilon_{q k}<\left(\frac{\psi_{j_{k}-1}-\left(\alpha_{k} z_{q k}+\sigma_{j_{k}}\right)}{\lambda_{q k}}\right)\right)\right) \\
& =\Lambda_{\varepsilon k}\left(\left(\frac{\psi_{j_{k}}-\left(\alpha_{k} z_{q k}+\sigma_{j_{k}}\right)}{\lambda_{q k}}\right)\right)-\Lambda_{\varepsilon k}\left(\left(\frac{\psi_{j_{k}-1}-\left(\alpha_{k} z_{q k}+\sigma_{j_{k}}\right)}{\lambda_{q k}}\right)\right)-\left(\operatorname { P r } \left[v_{q k}<-\beta_{k} x_{q k}, \varepsilon_{q k}<\right.\right. \\
& \left.\left.\left(\frac{\psi_{j_{k}}-\left(\alpha_{k} z_{q k}+\sigma_{j_{k}}\right)}{\lambda_{q k}}\right)\right]-\operatorname{Pr}\left[v_{q k}<-\beta_{k} x_{q k}, \varepsilon_{q k}<\left(\frac{\psi_{j_{k}-1}-\left(\alpha_{k} z_{q k}+\sigma_{j_{k}}\right)}{\lambda_{q k}}\right)\right]\right)
\end{aligned}
$$

The joint probability of Equation (15) can be expressed by using the copula function in equation (13) as: 


$$
\begin{aligned}
\operatorname{Pr}\left(\eta_{q k}=1, y_{q k}\right. & \left.=j_{k}\right) \\
& =\Lambda_{\varepsilon k}\left(\frac{\psi_{j_{k}}-\left(\alpha_{k} z_{q k}+\sigma_{j_{k}}\right)}{\lambda_{q k}}\right) \\
& -\Lambda_{\varepsilon k}\left(\left(\frac{\psi_{j_{k}-1}-\left(\alpha_{k} z_{q k}+\sigma_{j_{k}}\right)}{\lambda_{q k}}\right)\right) \\
& -\left[C_{\theta q}\left(U_{q, j}^{k}, U_{q}^{k}\right)-C_{\theta q}\left(U_{q, j-1}^{k}, U_{q}^{k}\right)\right]
\end{aligned}
$$

Thus, the likelihood function with the joint probability expression in equation (16) for incident type and duration level outcomes can be expressed as:

$$
L=\prod_{q=1}^{Q}\left[\prod_{k=1}^{K} \prod_{j=1}^{J}\left\{\operatorname{Pr}\left(\eta_{q k}=1, y_{q k}=j_{k}\right)\right\}^{\omega_{q j k}}\right]
$$

where, $\omega_{\mathrm{qjk}}$ is dummy with $\omega_{\mathrm{qjk}}=1$ if the incident $q$ sustains incident type $k$ and an incident duration level of $j$ and 0 otherwise. All the parameters in the model are then consistently estimated by maximizing the logarithmic function of L. The parameters to be estimated in the model are: $\beta_{\mathrm{k}}$ and $\varrho$ in the SMNL model component, $\alpha_{k}$ and $\psi_{j_{k}}$ in GGOL model component, and finally $\gamma_{\mathrm{k}}$ in the dependency component.

\subsection{Summary}

The main objective of this study is to develop a copula based joint model system of incident type and incident duration using scaled multinomial logit model and group generalized ordered logit model, respectively. This chapter presented a detailed discussion of the econometric 
methodology employed in this study. The next chapter will present a detailed description of the dataset used for our analysis. 


\section{CHAPTER 4: DATA PREPARATION}

The previous chapter discussed on econometric methodology employed in this study. This chapter will provide a detailed discussion of the incident management dataset employed in our study. The first section of this chapter will describe the data sources used for the data preparation, second section will describe data preparation steps and the third section will describe the dependent and independent variables used for the analysis.

\subsection{Data Source}

The main data source for the current study is the incident management dataset compiled by the Florida Department of Transportation (FDOT). Event management data collected over six years from 2012 to 2017 for Greater Orlando region was processed to prepare the final dataset. The study region consists of a number of major highways of the Greater Orlando Region including Interstate - 4 (I-4), East-West expressway (toll road 408), Beachline expressway (toll road 528), Central Florida Greenway (toll road 417), Daniel Webster Western Beltway (toll road 429) and other arterials, collectors and local roads.

\subsection{Data Preparation}

The study is confined to the incidents with an official reported response compiled by FDOT. The final dataset, after removing events without any response, consists of 326,348 incident records. In preparation of estimation sample, 2000 incidents were randomly sampled for each year (2012 to 2017), to create an overall estimation sample of 12,000 records. For validation test, on the other hand, 2500 records from each year were sampled randomly from the unused data resulting 
in a validation dataset of 15,000 records. Three incident types indicating crash, debris and other incidents were considered. Other incidents include disabled vehicles, abandoned vehicle, and tire blown. Initial model estimation efforts considered "other category" as separate categories. However, the model estimation results indicated the absence of substantial differences between disabled, abandoned and tire blown categories. Hence, these alternatives were merged in the other category. For incident duration, we have considered 10 categories $(>0-5,>5-10,>10-15,>15-20$, $>20-25,>25-30,>30-50,>50-80,>80-120$ and $>120$ minute). Distribution of incident duration categories for each incident type is presented in Figure 4.1. From Figure 4.1, we can observe that incident duration profile varies substantially across different incident type categories. Crash events has a left skewed duration distribution while the other two incident types have a right skewed distribution. Given these clear differences across the three incident types, developing a single duration model (as considered in existing literature) can potentially result in biased and incorrect parameter estimation.

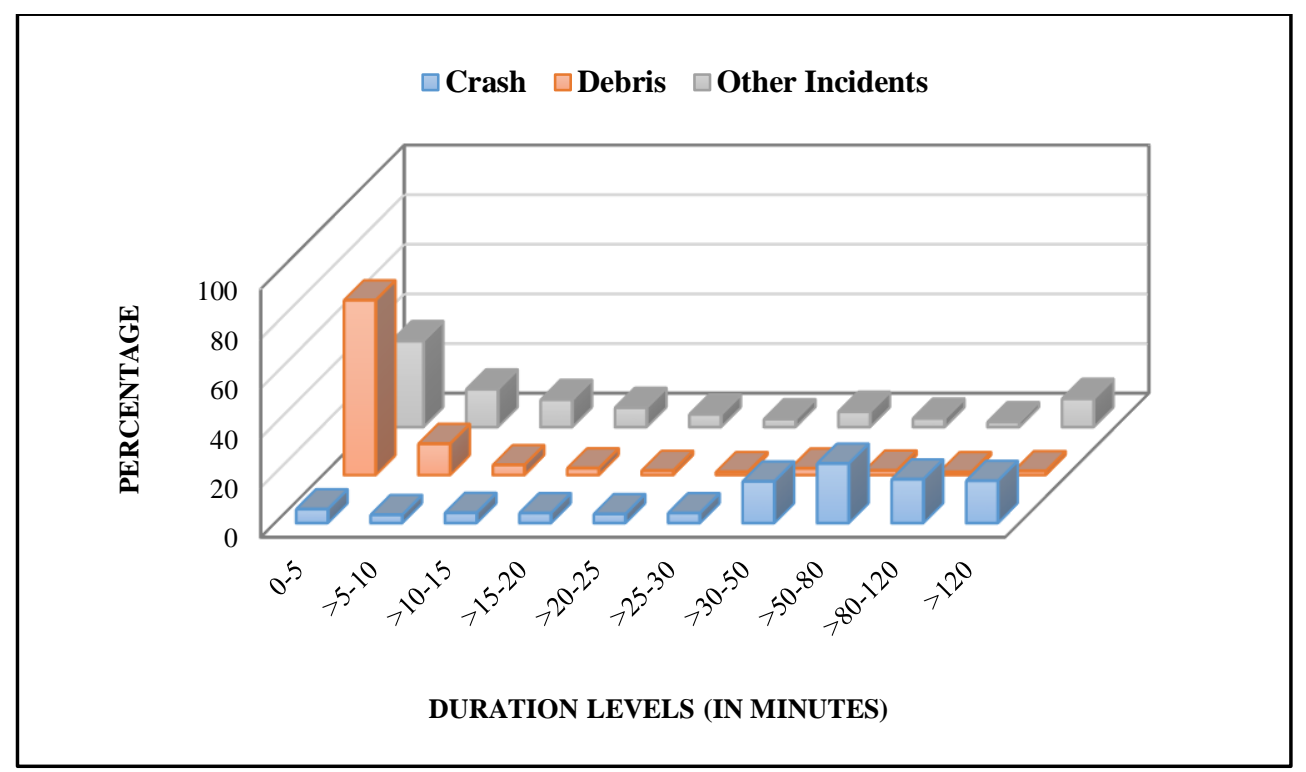

Figure 4.1 Distribution of Incident Duration for Different Incident Types 


\subsection{Independent Variables}

The incident management dataset is augmented with several exogenous variables. These variables are sourced from American Community Survey, Florida Geographic Data Library, FDOT and Florida Automated Weather Network databases. Exogenous variables considered can be classified into six broad categories: incident characteristics, traffic characteristics, roadway characteristics, weather conditions, built environment and socio-demographic characteristics. Incident characteristics include number of responders, first responder and notified agency. Roadway characteristics considered include location in terms of intersection and interchange, roadway's functional class, geometric characteristics, average annual daily traffic (AADT). Traffic characteristics include time of the day to accommodate hourly variation of traffic and weekday/weekend. Weather condition include season and rain. Built environment characteristics include land-use mix variable, number of business centers, commercial establishment, recreational establishment, restaurants and other establishments in 0.5 mile buffer area of each incident. Sociodemographic characteristics include population and median income in the 0.5 mile buffer area.

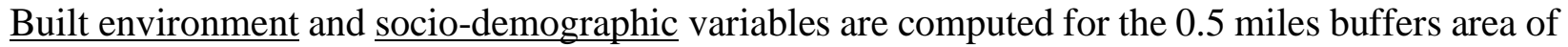
each incident location by using ArcGIS. The descriptive statistics of exogenous variables found significant in the final specified model are presented in Table 4.1.

\section{Table 4.1 Description of Model Estimation Sample}

\begin{tabular}{|l|l|l|l||}
\hline \hline Variable & Variable Description & Freq. & Percentage (\%) \\
\hline \multicolumn{4}{|c|}{ Dependent Variable for Incident Type Component } \\
\hline Crash & & 2044 & 17.033 \\
\hline Debris & & 2197 & 18.308 \\
\hline Others type of incidents & 7759 & 64.658 \\
\hline \multicolumn{4}{|l|}{} \\
\hline
\end{tabular}




\begin{tabular}{|c|c|c|c|}
\hline Variable & Variable Description & Freq. & Percentage $(\%)$ \\
\hline $\mathrm{T} 1$ & $>0-5$ minute & 4353 & 36.275 \\
\hline $\mathrm{T} 2$ & $>5$-10minute & 1523 & 12.692 \\
\hline $\mathrm{T} 3$ & $>10-15$ minute & 1025 & 8.542 \\
\hline T4 & $>15-20$ minute & 747 & 6.225 \\
\hline T5 & $>20-25$ minute & 507 & 4.225 \\
\hline T6 & $>25-30$ minute & 357 & 2.975 \\
\hline $\mathrm{T} 7$ & $>30-50$ minute & 880 & 7.333 \\
\hline T8 & $>50-80$ minute & 798 & 6.65 \\
\hline T9 & $>80-120$ minute & 542 & 4.517 \\
\hline T10 & $>120$ minute & 1268 & 10.567 \\
\hline \multicolumn{4}{|c|}{ Independent Variables (Categorical) } \\
\hline \multicolumn{4}{|c|}{ Incident Characteristics } \\
\hline \multicolumn{4}{|c|}{ First responder } \\
\hline Road Ranger & First responder is the Road Rangers & 10417 & 86.808 \\
\hline Other agencies & First responder is Other agencies & 1583 & 13.192 \\
\hline \multicolumn{4}{|l|}{ Notified Agency } \\
\hline Road Ranger (RR) & Incidents were notified to the Road Rangers & 5248 & 43.733 \\
\hline Other agencies & Incidents were notified to the Other agencies & 6752 & 56.267 \\
\hline \multicolumn{4}{|c|}{ Roadway Characteristics } \\
\hline \multicolumn{4}{|c|}{ At interchange or not } \\
\hline At interchange & Incident was identified on an interchange & 1323 & 11.025 \\
\hline Non-interchange & Incident was not identified on an interchange & 10677 & 88.985 \\
\hline \multicolumn{4}{|l|}{ At intersection or not } \\
\hline At intersection & Incident was identified on an intersection & 3055 & 25.458 \\
\hline Non-intersection & Incident was not identified on an intersection & 8945 & 74.542 \\
\hline \multicolumn{4}{|c|}{ Functional Classification } \\
\hline Rural Highway & Incident was identified on rural highway & 803 & 6.692 \\
\hline Rural Arterial & Incident was identified on rural arterial & 485 & 4.042 \\
\hline Rural Local & Incident was identified on rural local road & 53 & 0.442 \\
\hline Urban Interstate & Incident was identified on urban interstate & 3535 & 29.458 \\
\hline Urban Freeway & Incident was identified on urban freeway & 2980 & 24.833 \\
\hline Urban Arterial & Incident was identified on urban arterial & 2065 & 17.208 \\
\hline Urban Local & Incident was identified on urban local road & 2079 & 17.325 \\
\hline \multicolumn{4}{|l|}{ Posted speed limit } \\
\hline Speed limit<55 & Posted speed limit is less than or equal to $55 \mathrm{mph}$ & 4913 & 40.942 \\
\hline Speed limit $>55$ & Posted speed limit is higher than $55 \mathrm{mph}$ & 7087 & 59.058 \\
\hline \multicolumn{4}{|l|}{ Traffic Condition } \\
\hline \multicolumn{4}{|l|}{ Weekend/Weekday } \\
\hline Weekday & Monday - Friday & 9196 & 76.633 \\
\hline Weekend & Saturday and Sunday & 2804 & 23.367 \\
\hline
\end{tabular}




\begin{tabular}{|c|c|c|c|}
\hline Variable & Variable Description & Freq. & Percentage $(\%)$ \\
\hline \multicolumn{4}{|l|}{ Time of the day } \\
\hline $6 a m-9 a m$ & & 1822 & 15.183 \\
\hline $9 \mathrm{am}-4 \mathrm{pm}$ & & 5151 & 42.925 \\
\hline $4 \mathrm{pm}-6 \mathrm{pm}$ & & 1877 & 15.642 \\
\hline $6 \mathrm{pm}-9 \mathrm{pm}$ & & 1826 & 15.217 \\
\hline $9 \mathrm{pm}-6 \mathrm{am}$ & & 1325 & 11.042 \\
\hline \multicolumn{4}{|c|}{ Weather Condition } \\
\hline \multicolumn{4}{|c|}{ Season } \\
\hline Spring & March, April and May & 2910 & 24.25 \\
\hline Summer & June, July and August & 3193 & 26.608 \\
\hline Fall & September, October and November & 3124 & 26.033 \\
\hline Winter & December, January and February & 2773 & 23.108 \\
\hline \multicolumn{4}{|c|}{ Independent Variables (Ordinal) } \\
\hline Variable & & Mean & Min/Max \\
\hline \multicolumn{4}{|c|}{ Incident Characteristics } \\
\hline No. of responders & No. of responders involved in clearance & 1.175 & $1.000 / 8.000$ \\
\hline Time elapsed & Time since 2012 in year & 2.500 & $0.000 / 5.000$ \\
\hline \multicolumn{4}{|c|}{ Independent Variables (Continuous) } \\
\hline \multicolumn{4}{|c|}{ Roadway Characteristics } \\
\hline AADT & $\operatorname{Ln}(\mathrm{AADT} / 10000)$ & 1.421 & $0.030 / 3.033$ \\
\hline Inside shoulder & Ln(Inside shoulder width in $\mathrm{ft}$ ) & 2.056 & $0.693 / 3.611$ \\
\hline Outside shoulder & Ln(Outside shoulder width in $\mathrm{ft}$ ) & 2.009 & $0.693 / 3.045$ \\
\hline Median width & $\operatorname{Ln}($ Median width in $\mathrm{ft})$ & 3.698 & $1.099 / 5.889$ \\
\hline \multicolumn{4}{|c|}{ Weather Condition } \\
\hline Rain & $\begin{array}{l}\text { Amount of rain in inch at the hour of incident } \\
\text { occurrence }\end{array}$ & 0.006 & $0.000 / 1.617$ \\
\hline \multicolumn{4}{|c|}{ Built Environment } \\
\hline Business & $\operatorname{Ln}$ (No. of business establishments in 0.5 mile buffer) & 0.101 & $0.000 / 1.609$ \\
\hline Commercial & $\begin{array}{l}\text { Ln(No. of commercial establishment in } 0.5 \text { mile } \\
\text { buffer) }\end{array}$ & 0.095 & $0.000 / 1.792$ \\
\hline Recreational & $\begin{array}{l}\text { Ln(No. of recreational establishment in } 0.5 \text { mile } \\
\text { buffer) }\end{array}$ & 0.271 & $0.000 / 2.565$ \\
\hline Restaurant & $\operatorname{Ln}($ No. of restaurants in $0.5 \mathrm{mile}$ buffer) & 1.111 & $0.000 / 4.357$ \\
\hline CBD distance & Ln(Distance from central business district in miles) & 1.754 & $-2.182 / 3.444$ \\
\hline Land-use mix & $\begin{array}{l}\text { Land-use in computed as } \frac{-\Sigma_{k}\left(p_{k}\left(\ln p_{k}\right)\right)}{\ln N} \text {, where } \boldsymbol{k} \text { is } \\
\text { the category of land-use, } \boldsymbol{p} \text { is the proportion of the } \\
\text { developed land area, } \boldsymbol{N} \text { is the number of land-use } \\
\text { categories within a buffer }\end{array}$ & 0.377 & $0.000 / 0.963$ \\
\hline \multicolumn{4}{|c|}{ Socio-demographic Characteristics } \\
\hline Population & Ln(Total population in 0.5 mile buffer $)$ & 6.805 & $2.652 / 8.721$ \\
\hline Median income & $\begin{array}{l}\text { Ln(Average median income in } 0.5 \text { mile buffer in } \\
\text { thousand) }\end{array}$ & 4.211 & $3.488 / 4.997$ \\
\hline
\end{tabular}




\subsection{Summary}

This chapter provides data source, and data preparation procedure including a detailed description of the dependent and the independent variables. The next chapter will present the model estimates and discuss the results in detail. 


\section{CHAPTER 5: MODEL RESULTS}

This chapter provides results of the proposed copula based joint system including estimates for both incident type component and incident duration component. Besides, first section of this chapter provides model selection procedure where data fit of different combination of copulas are examined.

\subsection{Model Selection}

The empirical analysis involves the estimation of models by using six different copula structures: a) FGM, b) Frank, c) Gumbel, d) Clayton, e) Joe and f) Gaussian copulas. A series of models have been estimated in the current study context. First, an independent copula model (separate SMNL and GGOL models) is estimated to establish a benchmark for comparison. Second, 6 different models that restricted the copula dependency structure across the three incident types and incident duration models to be the same are estimated. Third, based on the copula parameter significance for each incident type, copula models that allow for different dependency structures for different incident type and incident duration combinations are estimated (for example Frank copula for the first two incident types and Clayton copula for other incident type). Fourth, joint models with different copula profiles are further augmented by parameterizing the copula profiles. Finally, to determine the most suitable copula model (including the independent copula model), a comparison exercise is undertaken. The alternative copula models estimated are non-nested and hence, cannot be tested using traditional log-likelihood (LL) ratio test. We employ the Bayesian Information Criterion (BIC) to determine the best model among all copula models without parameterization. 
The computed BIC (LL, Number of parameters) value of the independent model is $62434.01(-30709.80,108)$. With single copula dependency structure, the best model fit is obtained for Frank with BIC value of 62336.31 ( $\mathrm{LL}=-30698.50$, No. of parameters $=100)$. However, the lowest BIC value is obtained for a combination model of Frank-Clayton-Frank copulas (Frank copula structure for crash and other incident types and Clayton dependency structure for debris) and the BIC value is found to be 62335.11 ( $\mathrm{LL}=-30697.92$, No. of parameters $=100)$. Subsequently, the copula profile for the Frank-Clayton-Frank model has been parameterized. The copula model with and without parameterizations are nested within each other and can be compared by employing log-likelihood ratio test. The LL value for the parameterized FrankClayton-Frank copula model is found to be LL $=-30693.72($ No. of parameters $=101, \mathrm{BIC}=$ 62336.10). The log-likelihood ratio test yields a test statistic value of 8.40 which is substantially larger than the critical chi-square value (6.635) with 1 degrees of freedom at $99 \%$ level of significance. Thus, the comparison exercise confirms the importance of allowing the dependency profile to vary across different records. In presenting the effects of exogenous variables in the joint model specification, we will restrict ourselves to the discussion of the Frank-Clayton-Frank specification with parameterization.

\subsection{Model Results}

In this section, model outcomes for incident type component and incident duration component are provided. Besides, estimation results are discussed to understand the factors influencing incident type and incident duration. 


\subsubsection{Incident Type Model Component}

Table 5.1 provides parameter estimates of incident type model component. A positive (negative) value of the parameters in Table 5.1 indicates higher (lower) propensity of the corresponding incident category compared to the base category.

\subsubsection{Roadway Characteristics}

Among roadway characteristics, interchange variable impact indicates that at interchange locations, the likelihood of debris incidence is higher while at intersections, the likelihood of crashes is higher. Incidents on rural highways are more likely to be crashes while less likely to be debris. The relationship is reversed for rural arterials. For rural local roads, crash incidences are found to be higher. On urban interstate, the results indicate higher possibility for crash and a lower possibility for debris incidents. The relationship is reversed for urban freeways. On urban arterials, the possibility of crash incident type is likely to be higher.

Estimation result for posted speed limit indicates that the roadway speed limit being greater than 55 has a negative impact on the likelihood of crash incidence and positive influence on debris incidence. Parameter estimate for AADT indicates that increasing AADT is likely to reduce the possibility of Debris incidences. Shoulder width and median width variables have significant impacts on incident types. Specifically, with the increase in inside shoulder width, the probability of crash incidence is found to be higher. On the other hand, increasing width of the outside shoulder is likely to reduce the possibility of crash and debris incidents. This is expected because with increasing outside shoulder width more space for disabled or abandoned vehicles is available (a major share of the Other alternative). Median width variable is negatively associated with crash and positively associated with debris incidents. 


\subsubsection{Traffic Characteristics}

Traffic characteristics prior to the occurrence of incident might affect the potential incident type. However, it is not feasible to generate detailed traffic information across all the incident records considered in our analysis. Hence, as potential surrogates reflecting traffic conditions, we considered the time period and day of the week. The results indicate that all time periods from 6 am $-9 \mathrm{pm}$ are less likely to result in crash. The possibility of crashes is particularly lower in the time period $9 \mathrm{am}-4 \mathrm{pm}$. At the same time, the results indicate that debris incidences are more likely to occur during the $6 \mathrm{am}-9 \mathrm{pm}$ time period. The probability is particularly higher for debris during time period $6 \mathrm{am}-4 \mathrm{pm}$. Finally, the day of the week parameters indicate that the likelihood of debris incidence is lower on weekdays (relative to weekends).

\subsubsection{Weather Conditions}

The variables tested for seasonality resulted in a significant parameter for spring. The result indicates lower propensity for crash during spring season. The results for Rain variable indicate that in the presence of rain, crash incidences are likely to be higher. The result is expected in Florida with tropical weather where heavy showers appear in short time frame affecting overall road safety.

\subsubsection{Built Environment}

Incident type is affected by crash proximity to central business district (CBD). Specifically, as the distance of the incident location to CBD increases the likelihood of crash and debris increases. Several land-use variables affect incident type likelihood. Business and restaurant land use contribute to lower debris incidence while recreational land use contributes to higher debris 
incidence. Commercial and restaurant land use contribute to higher crash possibilities. Finally, overall land-use mix variable is found to have a positive effect on debris variable.

\subsubsection{Socio-demographic Variables}

Population density and median income in the proximity of incident are found to be significant predictors of incident type. Higher population density increases probability of an incident being debris and reduces the likelihood of an incident being crash relative to other incidents. The result is reflective of the enhanced safety in highly populated areas. Similarly, incidents occurring in high income areas are less likely to be a crash.

\subsubsection{Scale parameter}

To accommodate for difference in incident type with time, we generated the time elapsed variable (time since 2012). The estimated model result indicates that the variance of the error term for the time elapsed variable increases with time highlighting the impact of unobserved time specific factors.

Table 5.1 Parameter Estimates for Incident Type Component (SMNL Model Results)

\begin{tabular}{|c|c|c|c|c|c|c|}
\hline \multirow{2}{*}{ Variable } & \multicolumn{2}{|l|}{ Crash } & \multicolumn{2}{|l|}{ Debris } & \multicolumn{2}{|c|}{ Other Incidents } \\
\hline & Est. & t-Stat & Est. & t-Stat & Est. & t-Stat \\
\hline Constant & 7.6596 & 9.9390 & -5.9350 & -10.2680 & -- & -- \\
\hline \multicolumn{7}{|c|}{ Roadway Characteristics } \\
\hline \multicolumn{7}{|c|}{ At Interchange or not (Base: Non-interchange) } \\
\hline At interchange & $--^{1}$ & -- & 0.9211 & 9.9460 & -- & -- \\
\hline \multicolumn{7}{|c|}{ At intersection or not (Base: Non-intersection) } \\
\hline At intersection & 0.1787 & 2.176 & -- & -- & -- & \\
\hline \multicolumn{7}{|c|}{ Function class of roadway (Base: Urban Local) } \\
\hline Rural highway & 0.4979 & 2.601 & -0.5990 & -2.048 & -- & -- \\
\hline
\end{tabular}




\begin{tabular}{|c|c|c|c|c|c|c|}
\hline \multirow{2}{*}{ Variable } & \multicolumn{2}{|l|}{ Crash } & \multicolumn{2}{|l|}{ Debris } & \multicolumn{2}{|c|}{ Other Incidents } \\
\hline & Est. & t-Stat & Est. & t-Stat & Est. & t-Stat \\
\hline Rural arterials & -1.2389 & -4.3970 & 0.9905 & 4.5440 & -- & -- \\
\hline Rural local & 2.2113 & 4.3770 & -- & -- & -- & -- \\
\hline Urban interstate & 0.8258 & 5.7170 & -0.8513 & -5.122 & -- & -- \\
\hline Urban Freeway & -0.5846 & -3.7250 & 1.5622 & 11.709 & -- & -- \\
\hline Urban arterials & 0.4458 & 4.5400 & -- & -- & -- & -- \\
\hline \multicolumn{7}{|c|}{ Posted speed limit (Base: Speed limit<55) } \\
\hline Speed limit $>55$ & -0.4219 & -3.8180 & 0.3847 & 3.6670 & -- & -- \\
\hline AADT & -- & -- & -0.2971 & -4.8940 & -- & -- \\
\hline Inside shoulder & 0.1585 & 2.1560 & -- & -- & -- & -- \\
\hline Outside shoulder & -0.1880 & -2.3040 & -0.4233 & -5.878 & -- & -- \\
\hline Median width & -0.5487 & -8.7420 & 0.1502 & 1.9980 & -- & -- \\
\hline \multicolumn{7}{|l|}{ Traffic Condition } \\
\hline \multicolumn{7}{|c|}{ Time of the day (Base: $9 \mathrm{pm}-6 \mathrm{am})$} \\
\hline $6 \mathrm{am}-9 \mathrm{am}$ & -0.2782 & -2.3850 & 1.5825 & 7.0290 & -- & -- \\
\hline $9 \mathrm{am}-4 \mathrm{pm}$ & -0.6918 & -7.2730 & 1.5318 & 7.1820 & -- & -- \\
\hline $4 \mathrm{pm}-6 \mathrm{pm}$ & -0.2568 & -2.3760 & 1.1637 & 5.1630 & -- & -- \\
\hline $6 \mathrm{pm}-9 \mathrm{pm}$ & -0.4600 & -4.2390 & 0.9021 & 3.9670 & -- & -- \\
\hline \multicolumn{7}{|c|}{ Weekend/ Weekday (Base: Weekend) } \\
\hline Weekday & -- & -- & -0.4261 & -5.4610 & -- & -- \\
\hline \multicolumn{7}{|c|}{ Weather Conditions } \\
\hline \multicolumn{7}{|c|}{ Season (Base: Other seasons) } \\
\hline Spring & -0.2338 & -3.1960 & -- & -- & -- & -- \\
\hline Rain & 2.2397 & 4.1600 & -- & -- & -- & -- \\
\hline \multicolumn{7}{|l|}{ Built Environment } \\
\hline CBD Distance & 0.3397 & 6.9950 & 0.3598 & 5.1390 & -- & -- \\
\hline Business & -- & -- & -1.1775 & -7.3720 & -- & -- \\
\hline Commercial & 0.6877 & 5.8180 & -- & -- & -- & -- \\
\hline Recreational & -- & -- & 0.3336 & 4.0340 & -- & -- \\
\hline Restaurants & 0.1346 & 4.4310 & -0.1513 & -3.9760 & -- & -- \\
\hline Land-use mix & -- & -- & 0.4499 & 2.6560 & -- & -- \\
\hline \multicolumn{7}{|c|}{ Socio-demographic } \\
\hline Population & -0.4200 & -8.4150 & 0.3749 & 6.7340 & -- & -- \\
\hline Median income & -1.1809 & -9.2630 & -- & -- & -- & -- \\
\hline \multicolumn{7}{|l|}{ Scale Parameter } \\
\hline Time elapsed & Estimate & $0.0895(\mathrm{t}-$ & at $=10.49$ & & & \\
\hline
\end{tabular}

$1_{--}=$Attributes insignificant at $90 \%$ confidence level 


\subsubsection{Incident Duration Model Component}

Table 5.2 provides parameter estimates of the duration model for crash, debris and other incident type categories considered in the study. A positive (negative) value of the parameter in Table 5.2 indicates propensity for higher (lower) duration.

\subsubsection{Incident Characteristics}

Several incident characteristics such as number of responders, category of the first responder and notified agency are found to influence incident duration. In terms of number of responders, the incident duration is found to be higher with the increased number of responders for all duration models. The result might seem counterintuitive. However, the increase in the number of responders is representative of the seriousness of the incident. Thus, based on incident notification, for more serious incidents, a large number of responders are likely to arrive at a scene for assisting in incident clearance. Several agencies are involved in the incident notification and clearance activities. The results indicate that if Road Ranger is the notified agency then the incident durations are likely to be lower for debris and other incidents (see (Laman et al., 2018) for similar result). Incident durations are also found to be lower for all incident categories if Road Ranger is the first responder.

\subsubsection{Roadway Characteristics}

The roadway characteristics are found to have no impact on incident duration for crashes. The result is a reflection of the emphasis on crash incident clearance. The emphasis is warranted given the potential savings of life in the event of crash. For debris, the duration is likely to be longer on rural arterials. For other incidents, the roadway classification of rural arterials and urban 
freeways are found to have negative impact on the duration component. The results from our models are different from earlier research (Ghosh et al., 2014; Laman et al., 2018) and warrant further investigations. Roadway geometric characteristics are found to have no effect on incident duration for any incident categories.

\subsubsection{Traffic Characteristics}

For crash and debris, the model estimation results indicate that incident durations are likely to be higher during $9 \mathrm{pm}$ to 6 am (see (Chung, 2010) and (Laman et al., 2018) for similar findings). On the other hand, for disabled vehicles duration is likely to be longer in the 6 am to 9 am time period. For the time period between 9 am to $9 \mathrm{pm}$, the disabled vehicles incidence is likely to have shorter incident duration. On weekdays, duration of crash incidence is likely to be shorter (as is supported by earlier research (Laman et al., 2018). On the other hand, duration is longer for debris on weekdays. Overall, the results are an indication of infrastructure readiness for crash incident clearance and reduced emphasis on debris clearance during the daytime and weekdays.

\subsubsection{Weather Effects}

Only seasonal effects are found to affect incident duration. Specifically, the results indicate that incident duration for debris is likely to be of longer duration in summer.

\subsubsection{Built Environment}

As the distance from CBD increases, the time for clearance for crash incidences are found to be higher. The result is indicative of the presence of more incident clearance infrastructure around CBD. 


\subsubsection{Socio-demographic Variables}

While several socio-demographic variables were considered in the model only two variables offered statistically significant results in the incident duration component. As population increases, the model results indicate a reduction in duration for crash and other incidents. For debris incidents, the reduction in duration is associated with higher median income. Overall, the results indicate that the incident management authorities are likely to prioritize highly populated areas.

\subsubsection{Alternative specific constants}

The proposed duration model also allows for alternative specific effects on various duration categories. In our incident duration estimation, we consider various alternative specific constants based on model fit and sample sizes across each duration category. The estimation results of these parameters are reported in the second-row panel of Table 3. These constants are similar to constant in discrete choice models and do not have an interpretation after incorporating other variables.

\subsubsection{Variance Components}

As described in the methodology section, the variance of the GGOL model components are estimated as a function of observed exogenous variables. The parameter estimates of these components are presented in the third-row panel of Table 3. From the results, it can be found that the exogenous variables that contribute to the variance profile of duration model of crash incidences include notified agency is Road Rangers and number of responders. The only exogenous variable that contributes to the variance profile of duration model of debris is outside shoulder width. The exogenous variables that contribute to the variance profile of duration model 
of other incidents include AADT, at intersection, first responder is Road Rangers and the incident was notified to Road Rangers. Thus, these results highlight the presence of heteroscedasticity in the data.

\subsubsection{Dependence Effects}

As indicated earlier, the estimated Frank-Clayton-Frank copula based SMNL-GGOL model with parameterization provides the best fit in incorporating the correlation between incident type and incident duration. The result of the dependency profile is presented in the last row panel of Table 3. The results clearly highlight the presence of common unobserved factors affecting incident type and incident duration. The Frank copula dependency structure is associated with the crash and other incident categories, while the Clayton dependency structure is associated with the debris category. For the crash incident type, the Frank dependency is negative indicating that the unobserved factors that are likely to increase crash likelihood are likely to reduce the incident duration. The Frank dependency for other incidents offers similar results. The reader would note that for other incident type, the dependency parameter varies by season. Finally, for debris incident, Clayton copula parameter indicates that the unobserved factors affecting debris incident and its associated duration have a strong lower tail dependency.

\section{Table 5.2 Parameter Estimates for Incident Duration}

\begin{tabular}{||l|l|l|l|l|l|l||}
\hline \multirow{2}{*}{ Variables } & \multicolumn{2}{l|}{ Crash } & Debris & \multicolumn{2}{l||}{ Other Incidents } \\
\cline { 2 - 7 } & Est. & t-stat & Est. & t-stat & Est. & t-stat \\
\hline \multicolumn{7}{|c||}{ Propensity components } \\
\hline Constant & 104.2761 & 12.9790 & -12.6649 & -0.6340 & 78.3892 & 4.5180 \\
\hline Incident characteristics & \multicolumn{7}{|l|}{} \\
\hline No. of responders & 9.7250 & 10.0730 & 24.5795 & 4.4010 & 25.9121 & 4.4290 \\
\hline
\end{tabular}




\begin{tabular}{|c|c|c|c|c|c|c|}
\hline \multirow{2}{*}{ Variables } & \multicolumn{2}{|l|}{ Crash } & \multicolumn{2}{|l|}{ Debris } & \multicolumn{2}{|c|}{ Other Incidents } \\
\hline & Est. & t-stat & Est. & t-stat & Est. & t-stat \\
\hline \multicolumn{7}{|c|}{ First responder (Base: Other agencies) } \\
\hline Road Ranger & -9.2166 & -4.6170 & -27.5312 & -4.7480 & -37.0589 & -4.0290 \\
\hline \multicolumn{7}{|c|}{ Notified agency (Base: Other agencies) } \\
\hline Road Ranger & $--^{1}$ & -- & -36.8587 & -6.4270 & -49.5242 & -8.0620 \\
\hline \multicolumn{7}{|c|}{ Roadway Characteristics } \\
\hline \multicolumn{7}{|c|}{ Functional class (Base: Other classes) } \\
\hline Rural arterial & -- & -- & 13.2396 & 2.8060 & -102.6595 & -9.5910 \\
\hline Urban freeway & -- & -- & -- & -- & -27.8564 & -4.4550 \\
\hline \multicolumn{7}{|c|}{ Traffic characteristics } \\
\hline \multicolumn{7}{|c|}{ Time of the day (Base: $9 \mathrm{pm}-6 \mathrm{am})$} \\
\hline $6 a m-9 a m$ & -11.1390 & -3.8540 & -24.2698 & -3.2280 & 14.5904 & 2.2610 \\
\hline $9 \mathrm{am}-4 \mathrm{pm}$ & -10.7558 & -4.6140 & -21.5290 & -3.0470 & -40.7983 & -7.3300 \\
\hline $4 \mathrm{pm}-6 \mathrm{pm}$ & -5.8756 & -2.1250 & -25.9414 & -3.4110 & -36.9026 & -5.6730 \\
\hline $6 \mathrm{pm}-9 \mathrm{pm}$ & -7.8879 & -2.8990 & -20.1242 & -2.7090 & -22.5256 & -3.5450 \\
\hline \multicolumn{7}{|c|}{ Weekend/ Weekday (Base: Weekend) } \\
\hline Weekday & -3.9172 & -2.0310 & 6.0762 & 2.1960 & -- & -- \\
\hline \multicolumn{7}{|c|}{ Weather condition } \\
\hline \multicolumn{7}{|c|}{ Season (Base: Other Seasons) } \\
\hline Summer & -- & -- & 5.4717 & 2.1250 & -- & -- \\
\hline \multicolumn{7}{|c|}{ Built Environment } \\
\hline CBD distance & 4.0977 & 3.7370 & -- & -- & -- & -- \\
\hline \multicolumn{7}{|c|}{ Socio-demographic Characteristics } \\
\hline Population & -5.2669 & -5.7490 & -- & -- & -6.7246 & -4.0450 \\
\hline Median income & -- & -- & -8.2901 & -2.1660 & -- & -- \\
\hline \multicolumn{7}{|c|}{ Category-specific constants } \\
\hline Constant for $\mathrm{T} 1$ & 19.7306 & 7.3080 & 14.6056 & 9.6070 & 122.1130 & 27.4130 \\
\hline Constant for T2 & 8.7898 & 5.5190 & -- & -- & 73.8363 & 23.8800 \\
\hline Constant for $\mathrm{T} 3$ & -- & -- & -- & -- & 40.8383 & 19.5830 \\
\hline Constant for $\mathrm{T} 4$ & -- & -- & -- & -- & 16.4859 & 13.5050 \\
\hline Constant for T5 & -- & -- & -- & -- & -- & -- \\
\hline Constant for $\mathrm{T} 6$ & -- & -- & -- & -- & -- & -- \\
\hline Constant for $\mathrm{T} 7$ & -- & -- & -- & -- & -- & -- \\
\hline Constant for $\mathrm{T} 8$ & -- & -- & -- & -- & -- & -- \\
\hline Constant for $\mathrm{T} 9$ & 18.8899 & 14.1380 & 24.0710 & 7.2220 & -- & -- \\
\hline \multicolumn{7}{|c|}{ Variance components } \\
\hline Constant & 3.3264 & 57.6220 & 3.2171 & 42.1950 & 3.8284 & 53.9040 \\
\hline
\end{tabular}




\begin{tabular}{|c|c|c|c|c|c|c|}
\hline \multirow{2}{*}{ Variables } & \multicolumn{2}{|l|}{ Crash } & \multicolumn{2}{|l|}{ Debris } & \multicolumn{2}{|c|}{ Other Incidents } \\
\hline & Est. & t-stat & Est. & t-stat & Est. & t-stat \\
\hline No. of responders & -0.1324 & -5.5390 & -- & -- & -- & -- \\
\hline \multicolumn{7}{|c|}{ First responder (Base: Other agencies) } \\
\hline Road Ranger & -- & -- & -- & -- & 0.5878 & 8.4000 \\
\hline \multicolumn{7}{|c|}{ Notified agency (Base: Other agencies) } \\
\hline Road Ranger & 0.4490 & 6.4160 & -- & -- & -0.0711 & -2.3800 \\
\hline \multicolumn{7}{|c|}{ At intersection or not (Base: Non-intersection) } \\
\hline At intersection & -- & -- & -- & -- & 0.1458 & 2.8510 \\
\hline AADT & -- & -- & -- & -- & 0.0323 & 2.1030 \\
\hline Outside shoulder & -- & -- & 0.0594 & 2.1690 & -- & -- \\
\hline \multicolumn{7}{|c|}{ Dependence Effects } \\
\hline Constant & -2.5268 & -4.5610 & 4.8241 & 4.4080 & -1.5917 & -3.7590 \\
\hline \multicolumn{7}{|c|}{ Season (Base: Other seasons) } \\
\hline Summer & -- & -- & -- & -- & -0.8163 & -2.8940 \\
\hline
\end{tabular}

${ }_{1--}=$ Attributes insignificant at $90 \%$ confidence level

\subsection{Summary}

In this chapter, model selection steps based on data fit measures and model estimation results are presented. Additionally, estimation results are discussed in detail to understand the factors of incident type and incident duration. The next chapter will examine model performance, and provide elasticity analysis results, and model illustration. 


\section{CHAPTER 6: MODEL PERFORMANCE AND APPLICATION}

This chapter examines model performance based on validation analysis using a holdout sample. Then, elasticity analysis is performed to quantify the effects of exogenous variables on incident duration by incident type. Finally, application of the proposed copula based joint model is illustrated.

\subsection{Validation Analysis}

To test the predictive performance of the estimated model, a validation exercise with holdout sample is performed. For this validation test, 2500 records from each year are drawn randomly from the unused data resulting in a validation dataset of 15,000 records. For testing the predictive performance of the models, 25 data samples, of about 1000 records each, are randomly generated from the hold out validation sample consisting of 15,000 records. The average loglikelihood and BIC score for the copula model are $-3046.67[(-3089.91,-3003.44)]$ and 6792.93 $[(6705.32,6880.54)]$, respectively. The average log-likelihood and BIC score for the independent model are $-3050.62[(-3092.55,-3008.69)]$, and 6849.30 [(6764.22,6934.38)], respectively. The average log-likelihood and BIC score for the traditional model (single duration model using incident type as an independent variable) are -3150.97 [(-3193.39, -3108.55)], and 6800.64 [(6714.99, 6886.30)], respectively. For every individual sample, the predicted log-likelihood and BIC value for the copula model are better than the corresponding log-likelihood and BIC value for the independent and the traditional model. The validation result clearly reflects the superiority of joint model over independent and traditional model.

We also examine predictive performance by incident type: (a) All incidents, (b) crash, (c) debris and (d) other incidents. The predictive LL value box plots for the three models by these four categories are presented in Figure 6.1. For the overall sample comparison reflected in the first box 
plot comparison, it is clear that a single model that ignores duration profiles by incident type is outperformed by the two models that consider duration profiles by incident type (independent and copula models). Among incident type specific comparison, the models developed in our study outperform the traditional model for debris and other incident types. However, for crash incident records, the traditional model marginally outperforms the proposed models.
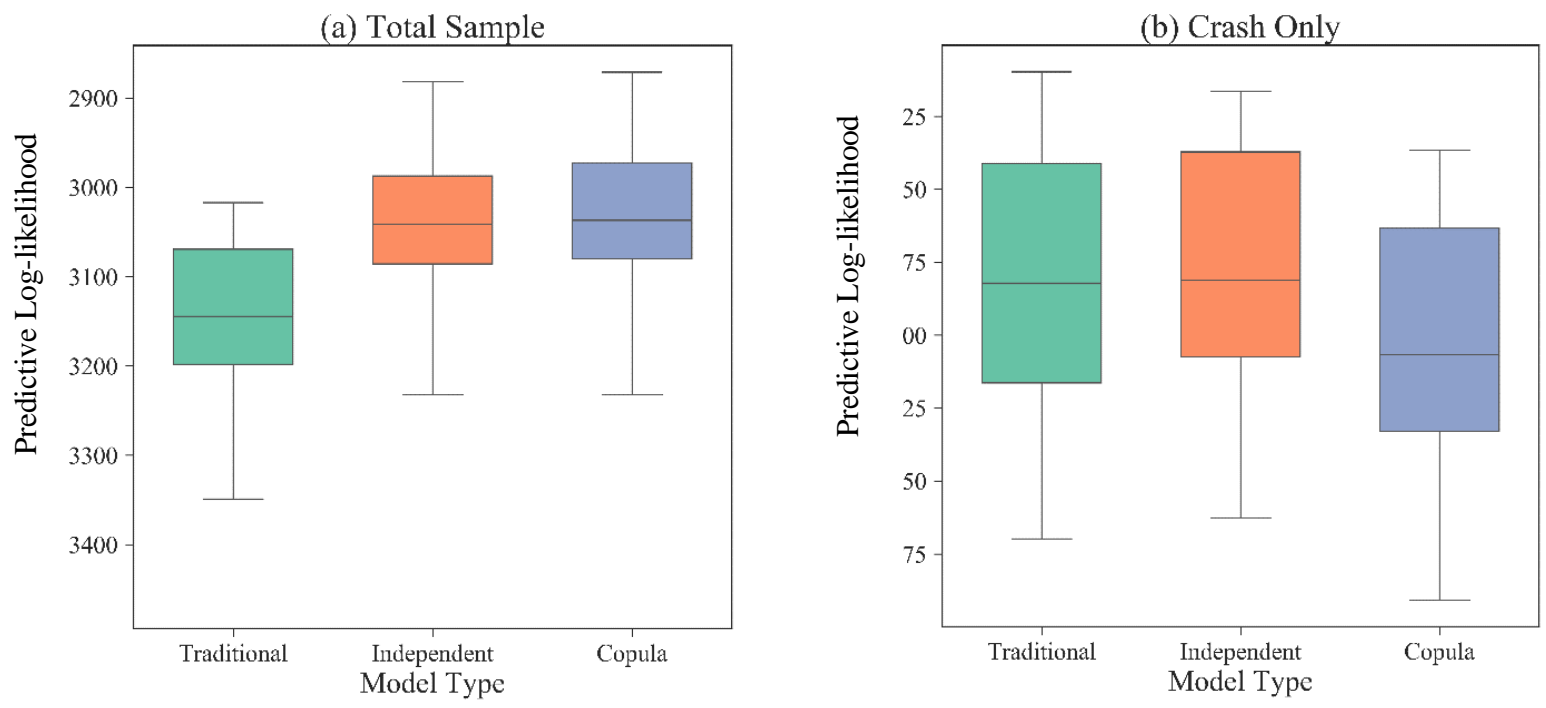

(c) Debris Only
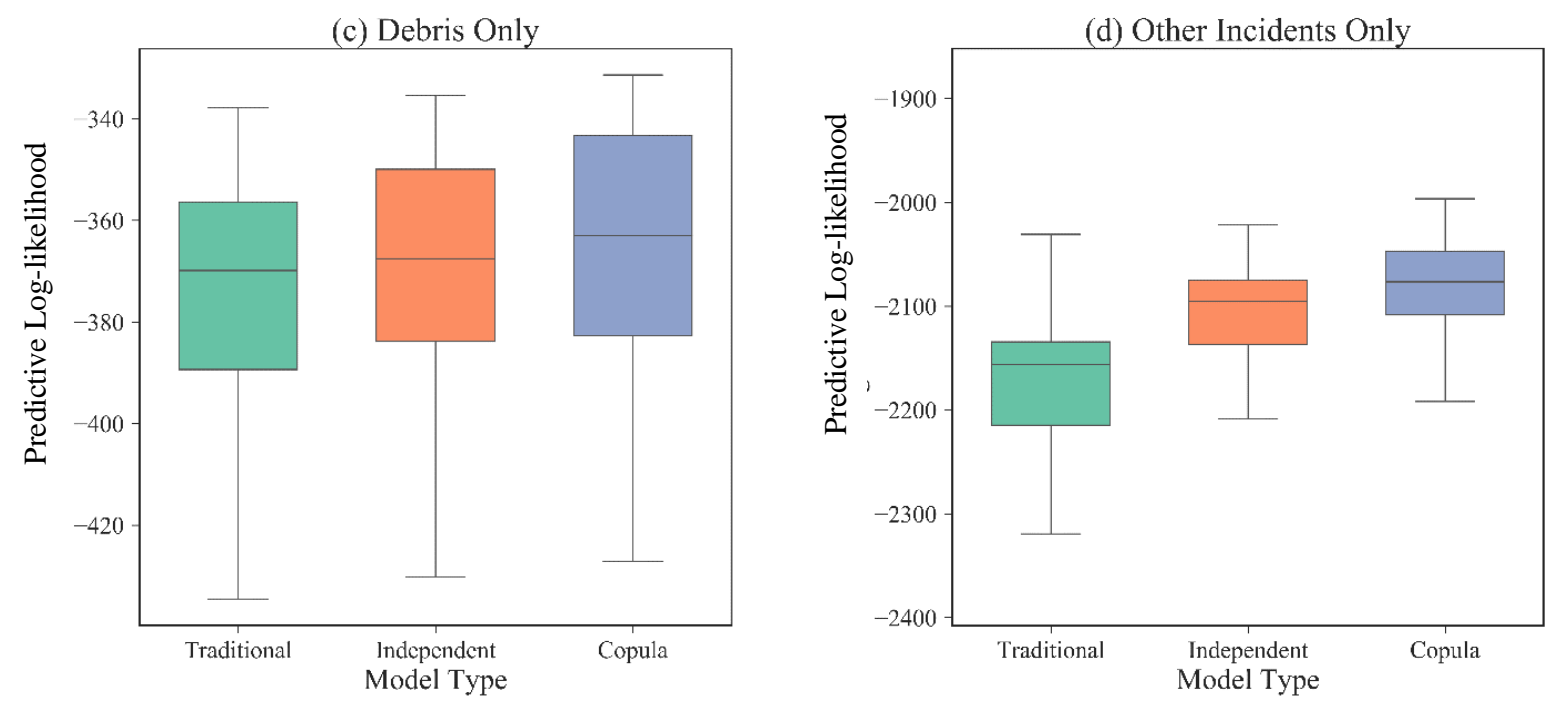

Figure 6.1 Comparison of Predictive Log-likelihood of the Three Models 


\subsection{Elasticity Analysis}

The parameter estimates of developed copula-based incident model can be utilized to identify whether an independent variable increases or decreases the probability of higher/lower order incident duration categories. But parameter estimates do not directly identify the magnitude of the change on the probability of a duration category. Therefore, elasticity effects for all independent variables with regard to incident duration were calculated. For the sake of brevity, we restrict ourselves to the presentation of elasticity values of the highest duration category in Table 6.1. Values presented in Table 6.1 reflect the percentage change in aggregate probability of the highest duration category due to the change in independent variables. From the elasticity analysis results, it is found that an increase in the number of responders increases the probability of higher ordered incident duration categories significantly. On the other hand, Road rangers being the first responder and the incident being notified by the Road Rangers reduce the probability of higher ordered duration categories. In case of traffic characteristics variables, crashes and debris occurring 6am to $9 \mathrm{pm}$ and other incidents occurring 9am to 9pm have lower duration compared to nighttime from 9am to 6am. With increasing CBD distance, duration of crashes increases significantly. With increased population in close proximity of crashes and other incidents, incident duration decreases significantly. Another socio-demographic characteristic, median income significantly influences duration of debris type of incident. Increase of median income decreases the probability of higher order duration category. Overall, the elasticity analysis results can be helpful to the incident management agencies to identify the dominant factors affecting incident duration. 
Table 6.1 Elasticity Analysis for Incident Duration

\begin{tabular}{|c|c|c|c|}
\hline Variables & Crash & Debris & Other Incidents \\
\hline \multicolumn{4}{|c|}{ Incident characteristics } \\
\hline No. of responders & 3.06799 & 6.83959 & 0.84843 \\
\hline \multicolumn{4}{|c|}{ First responder (Base: Other agencies) } \\
\hline Road Ranger & -14.82945 & -104.78980 & -4.92734 \\
\hline \multicolumn{4}{|c|}{ Notified agency (Base: Other agencies) } \\
\hline Road Ranger & 0.26746 & -65.26592 & -16.50839 \\
\hline \multicolumn{4}{|c|}{ Roadway Characteristics } \\
\hline \multicolumn{4}{|c|}{ Functional class (Base: Other classes) } \\
\hline Rural arterial & -- & 41.09485 & -23.75875 \\
\hline Urban freeway & -- & -- & -8.087557 \\
\hline \multicolumn{4}{|c|}{ Traffic characteristics } \\
\hline \multicolumn{4}{|c|}{ Time of the day (Base: 9pm - 6am) } \\
\hline 6am -9am & -17.55639 & -56.43968 & 4.531904 \\
\hline $9 \mathrm{am}-4 \mathrm{pm}$ & -16.94333 & -61.75876 & -12.17580 \\
\hline $4 p m-6 p m$ & -9.287986 & -55.22964 & -10.54608 \\
\hline $6 \mathrm{pm}-9 \mathrm{pm}$ & -12.47041 & -43.79461 & -6.61213 \\
\hline \multicolumn{4}{|c|}{ Weekend/ Weekday (Base: Weekend) } \\
\hline Weekday & -6.18817 & 15.51287 & -- \\
\hline \multicolumn{4}{|c|}{ Weather condition } \\
\hline \multicolumn{4}{|c|}{ Season (Base: Other Seasons) } \\
\hline Summer & -- & 14.96467 & -- \\
\hline \multicolumn{4}{|c|}{ Built Environment } \\
\hline CBD distance & 4.10584 & -- & -- \\
\hline \multicolumn{4}{|c|}{ Socio-demographic Characteristics } \\
\hline Population & -5.64136 & -- & -1.37324 \\
\hline Median income & -- & -8.72836 & -- \\
\hline
\end{tabular}

* Values indicate the percentage changes of aggregated probability of the highest duration category

\subsection{Model Illustration}

To demonstrate the applicability of the developed model, the final model was applied to generate response surface using duration categories, incident frequencies and selected independent variables for different incident types. In generating the values for plotting the response surface, the incident duration categories are identified based on probabilistic assignment by using predicted 
probabilities computed from the final copula model (Frank-Clayton-Frank parameterized). The probabilities are appropriately aggregated across categories to identify the corresponding incident frequencies. For example, incident frequencies of crashes are plotted against duration categories and number of responders in Figure 6.2a. The plotted surface shows that crash incidents are typically associated with longer clearance times and are likely to involve increased number of responders compared to other incident types. Figure $6.2 \mathrm{~b}$ presents crash incident frequencies by time of the day and indicates that crash frequency is the highest between 9am to $4 \mathrm{pm}$ compared to other time of the day. Similar to Figure 6.2a, crash incident frequencies are higher for longer duration levels. Figure $3 \mathrm{c}$ indicates that the likelihood of crash incidents is higher for locations between 5 to 10 miles from central business district. Figure $6.2 \mathrm{~d}$ presents other incident frequencies by duration category and time of the day. The reader would note that the plots provided are only a sample of the various illustrations that can be generated based on the independent variables in the models. The development of such response surface could be helpful for the incident management agencies to allocate their resources based on the reported incident scenarios.

\subsection{Summary}

Results of validation analysis is presented in this chapter which indicates superiority of the proposed model over the traditional approach and independent model of incident type and incident duration. Elasticity analysis and model application are also presented in this chapter. The next chapter will conclude this study by presenting overall findings and limitations of this research. 


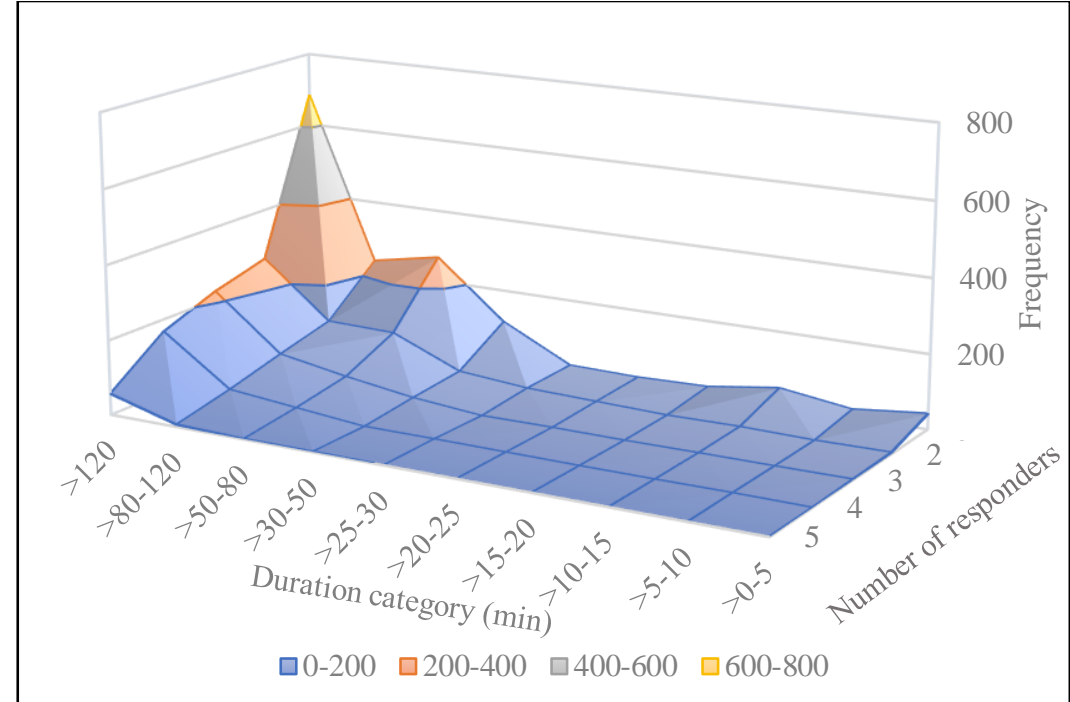

(a) Crash frequencies with respect to number of responders

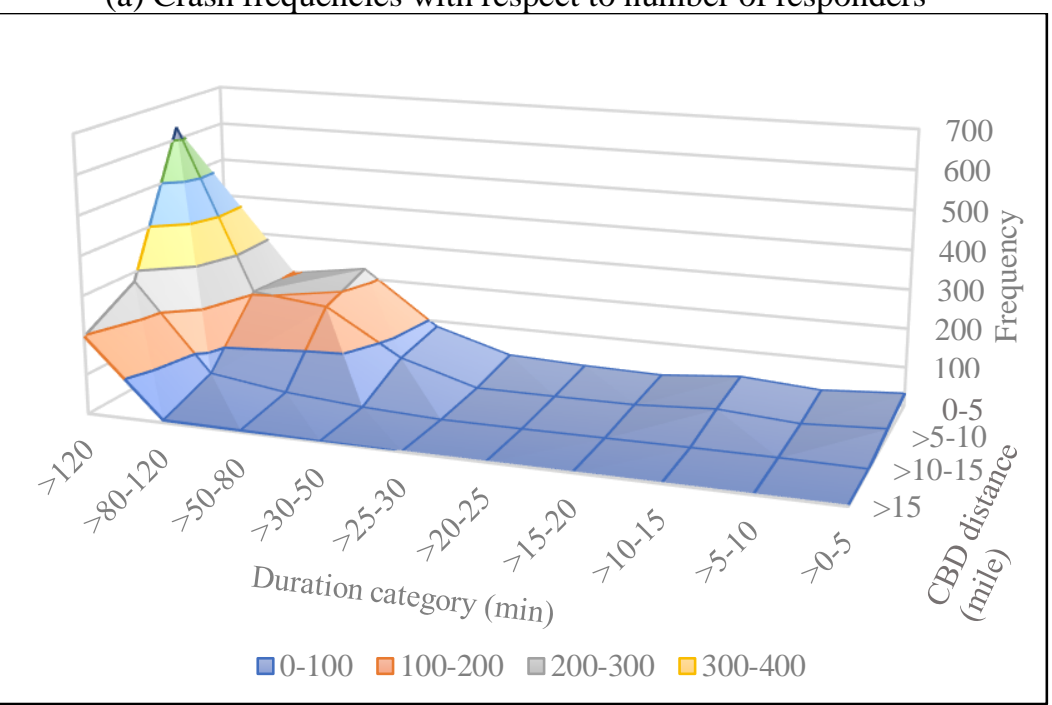

(c) Crash frequencies with respect to CBD distance

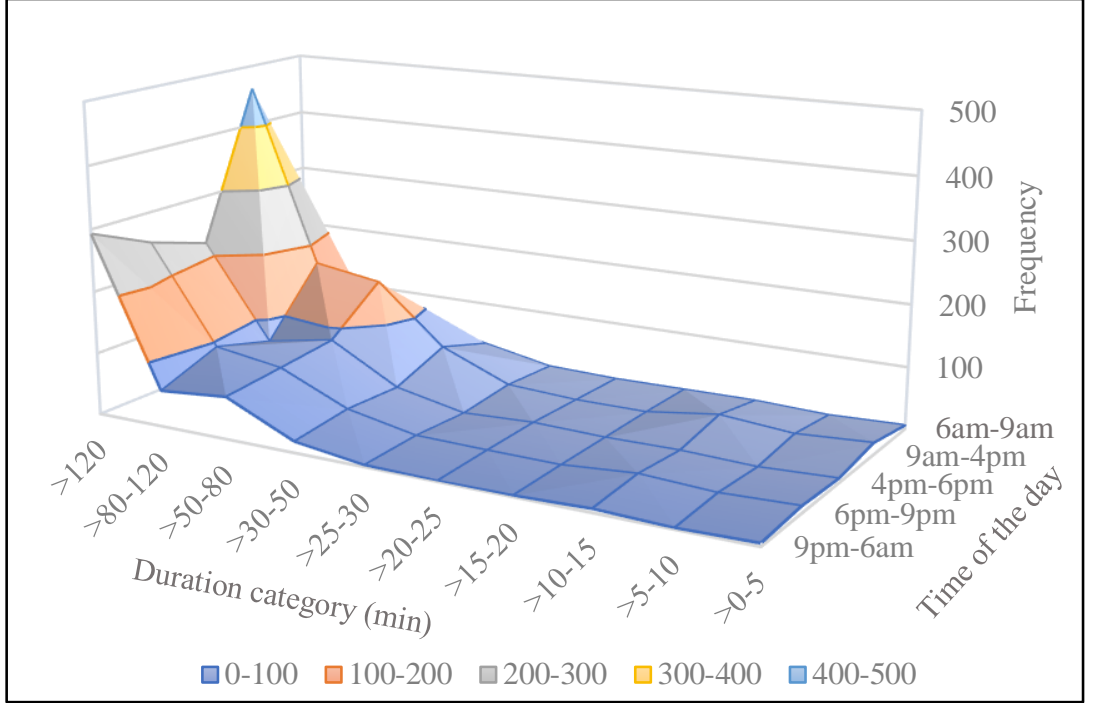

(b) Crash frequencies with respect to time of the day

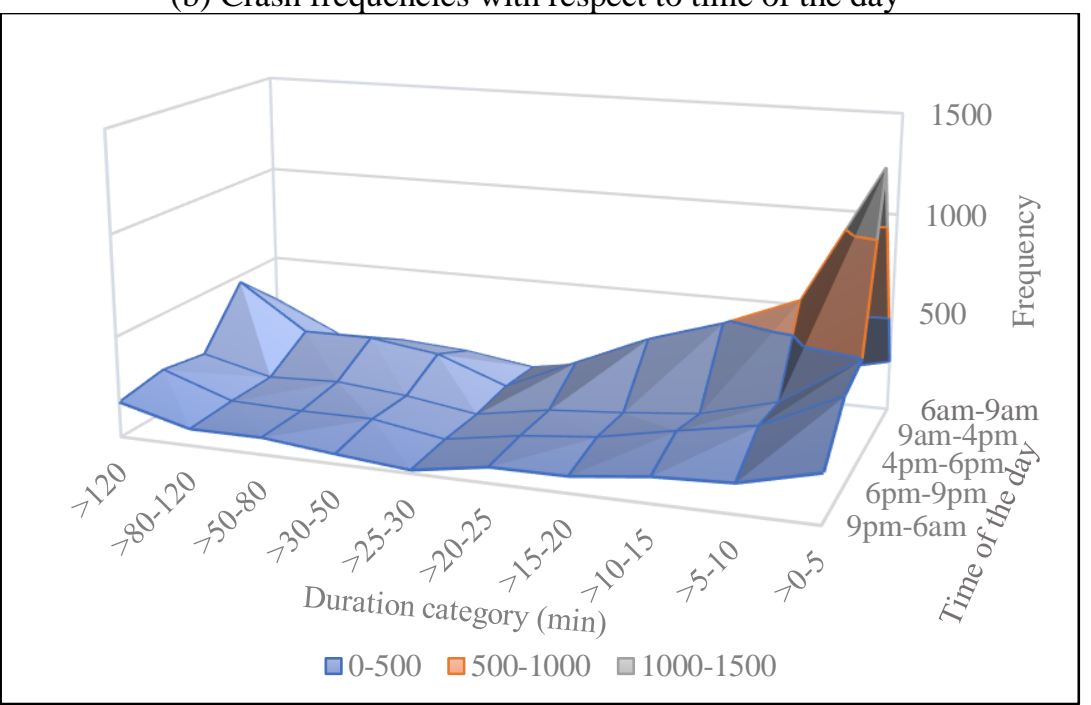

(d) Other Incidents frequencies with respect to time of the day

Figure 6.2 Response Surface for Predicted Incident Frequencies 


\section{CHAPTER 7: CONCLUSION}

To understand the impact of observed and unobserved effects on incident type and incident duration, this paper formulated and estimated a copula-based joint model with a scaled multinomial logit model (SMNL) system for incident type and a grouped generalized ordered logit (GGOL) model system for incident duration. The proposed model is estimated using FDOT's incident management data from Greater Orlando region, with a host of independent variables including incident characteristics, roadway characteristics, traffic condition, weather condition, built environment and socio-demographic characteristics. The current study contributes to incident duration literature in multiple ways. First, the current study posits that incident duration is strongly influenced by incident type and allows for distinct incident profile regimes. Further, the study accommodates for common unobserved factors affecting incident type and incident type within a closed form copula-based model structure. Second, the study using data from multiple years, develops a framework that accommodates for observed and unobserved temporal effects on incident type and incident duration. Finally, the proposed model system is estimated using a comprehensive set of exogenous variables.

The empirical analysis involves the estimation of models by using six different copula structures: 1) FGM, 2) Clayton, 3) Gumbel, 4) Frank, 5) Joe and 6) Gaussian. The parameterized Frank-Clayton-Frank copula system (Frank copula structure for crash and other incident type and Clayton dependency structure for debris) offered the best data fit for our empirical context. The model estimation results presented in the current paper suggest that the impact of exogenous variables vary (for some variables) in magnitude as well as in sign across incident types. To further understand the performance of the developed model, a comprehensive model performance 
evaluation and applicability exercise was conducted. The results from the exercise illustrate the value offered by the proposed model system.

The enhanced duration model can be employed by planning agencies to guide incident clearance as well as traffic congestion management. To elaborate, based on the model system, planning agencies can generate guidelines on incident duration times for important variables such as incident type, location and time of day. These guideline durations for incident clearance can allow agencies to identify the appropriate messaging signs (such as what is targeted demand for diversion) for route detours at the occurrence of an incident. 


\section{LIST OF REFERENCES}

Anowar, S., Eluru, N., \& Miranda-Moreno, L. F. (2016). Analysis of vehicle ownership evolution in Montreal, Canada using pseudo panel analysis. Transportation, 43(3), 531-548.

Behnood, A., \& Mannering, F. L. (2015). The temporal stability of factors affecting driver-injury severities in single-vehicle crashes: some empirical evidence. Analytic methods in accident research, 8, 7-32.

Bhat, C. R., \& Eluru, N. (2009). A copula-based approach to accommodate residential selfselection effects in travel behavior modeling. Transportation Research Part B: Methodological. Elsevier Ltd, 43(7), 749-765.

Chung, Y. (2010). Development of an accident duration prediction model on the Korean Freeway Systems. Accident Analysis and Prevention, 42(1), 282-289.

Chung, Y. S., Chiou, Y. C., \& Lin, C. H. (2015). Simultaneous equation modeling of freeway accident duration and lanes blocked. Analytic methods in accident research, 7, 16-28.

Dabbour, E. (2017). Investigating temporal trends in the explanatory variables related to the severity of drivers' injuries in single-vehicle collisions. Journal of traffic and transportation engineering (English edition), 4(1), 71-79.

Ding, C., Ma, X., Wang, Y., \& Wang, Y. (2015). Exploring the influential factors in incident clearance time: Disentangling causation from self-selection bias. Accident Analysis and Prevention, 85, 58-65.

FHWA EDC (2012). SHRP2 Traffic Incident Management Responder Training. URL http://www.fhwa.dot.gov/everydaycounts/edctwo/2012/pdfs/edc_traffic.pdf (accessed 7.15.2019). 
Garib, A., Radwan, A. E., \& Al-Deek, H. (2002). Estimating Magnitude and Duration of Incident Delays. Journal of Transportation Engineering, 123(6), 459-466.

Ghosh, I., Savolainen, P. T., \& Gates, T. J. (2014). Examination of factors affecting freeway incident clearance times: A comparison of the generalized $\mathrm{F}$ model and several alternative nested models. Journal of Advanced Transportation, 48(6), 471-485.

Hamad, K., Al-Ruzouq, R., Zeiada, W., Abu Dabous, S., \& Khalil, M. A. (2020). Predicting incident duration using random forests. Transportmetrica A: Transport Science, 16(3), 1269-1293.

Haule, H. J., Sando, T., Lentz, R., Chuan, C. H., \& Alluri, P. (2019). Evaluating the impact and clearance duration of freeway incidents. International journal of transportation science and technology, 8(1), 13-24.

HCM (2010). Highway capacity manual (Fifth edition). Washington, D.C.: Transportation Research Board. URL https://search.library.wisc.edu/catalog/9910110589002121 (accessed 7.12.2019).

Hong, J., Tamakloe, R., Park, D., \& Choi, Y. (2019). Estimating incident duration considering the unobserved heterogeneity of risk factors for trucks transporting HAZMAT on expressways. Transportation research record, 2673(2), 232-242.

INRIX (2018). URL http://inrix.com/scorecard/ (accessed 7.18.2019)

Javid, R. J., \& Javid, R. J. (2018). A framework for travel time variability analysis using urban traffic incident data. IATSS research, 42(1), 30-38.

Junhua, W., Haozhe, C., \& Shi, Q. (2013). Estimating freeway incident duration using accelerated failure time modeling. Safety Science. 54, 43-50. 
Ke, A., Gao, Z., Yu, R., Wang, M., \& Wang, X. (2017, May). A hybrid approach for urban expressway traffic incident duration prediction with Cox regression and random survival forests models. In 2017 IEEE/ACIS 16th International Conference on Computer and Information Science (ICIS) (pp. 113-118). IEEE.

Khattak, A. J., Schofer, J. L. \& Wang, M. H. (1995). A Simple Time Sequential Procedure for Predicting Freeway Incident Duration. Journal of Intelligent Transportation Systems, 2 (2), $113-138$.

Laman, H., Yasmin, S., \& Eluru, N. (2018). Joint modeling of traffic incident duration components (reporting, response, and clearance time): A copula-based approach. Transportation Research Record, 2672(30), 76-89.

Lee, Y., \& Wei, C. H. (2010). A computerized feature selection method using genetic algorithms to forecast freeway accident duration times. Computer-Aided Civil and Infrastructure Engineering. 25(2), 132-148.

Li, R., Pereira, F. C., \& Ben-Akiva, M. E. (2015). Competing risk mixture model and text analysis for sequential incident duration prediction, Transportation Research Part C: Emerging Technologies. 54, 74-85.

Ma, X., Ding, C., Luan, S., Wang, Y., \& Wang, Y. (2017). Prioritizing influential factors for freeway incident clearance time prediction using the gradient boosting decision trees method. IEEE Transactions on Intelligent Transportation Systems, 18(9), 2303-2310.

Mannering, F. (2018). Temporal instability and the analysis of highway accident data. Analytic methods in accident research, 17, 1-13. 
Marcoux, R., Yasmin, S., Eluru, N., \& Rahman, M. (2018). Evaluating temporal variability of exogenous variable impacts over 25 years: An application of scaled generalized ordered logit model for driver injury severity. Analytic methods in accident research, 20, 15-29.

Nam, D., \& Mannering, F. (2000). An exploratory hazard-based analysis of highway incident duration. Transportation Research Part A: Policy and Practice, 34(2), 85-102.

Ozbay, K., \& Noyan, N. (2006). Estimation of incident clearance times using Bayesian Networks approach. Accident Analysis and Prevention, 38(3), 542-555.

Shang, Q., Tan, D., Gao, S., \& Feng, L. (2019). A hybrid method for traffic incident duration prediction using BOA-optimized random forest combined with neighborhood components analysis. Journal of Advanced Transportation, 2019.

Sklar, A. (1973). Random variables, joint distribution functions, and copulas. Kybernetika, 9(6), $449-460$.

Tavassoli Hojati, A., Ferreira, L., Washington, S., \& Charles, P. (2013). Hazard based models for freeway traffic incident duration. Accident Analysis and Prevention, 52, 171-181.

Tavassoli Hojati, A., Ferreira, L., Washington, S., Charles, P., \& Shobeirinejad, A. (2014). Modelling total duration of traffic incidents including incident detection and recovery time. Accident Analysis and Prevention, 71, 296-305.

Valenti, G., Lelli, M., \& Cucina, D. (2010). A comparative study of models for the incident duration prediction. European Transport Research Review, 2(2), 103-111.

Wang, S., Li, R., \& Guo, M. (2018). Application of nonparametric regression in predicting traffic incident duration. Transport, 33(1), 22-31.

Wang, X., Chen, S., \& Zheng, W. (2013). Traffic Incident Duration Prediction based on Partial Least Squares Regression. Procedia - Social and Behavioral Sciences, 96, 425-432. 
Wu, W. W., Chen, S. Y., \& Zheng, C. J. (2011). Traffic incident duration prediction based on support vector regression. In ICCTP 2011: Towards Sustainable Transportation Systems (pp. 2412-2421).

Zhan, C., Gan, A., \& Hadi, M. (2011). Prediction of lane clearance time of freeway incidents using the M5P tree algorithm. IEEE Transactions on Intelligent Transportation Systems, 12(4), $1549-1557$.

Zou, Y., Ye, X., Henrickson, K., Tang, J., \& Wang, Y. (2018). Jointly analyzing freeway traffic incident clearance and response time using a copula-based approach. Transportation research part C: emerging technologies, 86, 171-182. 